\title{
A Computer Method for Rapid Design of Composite Steel-concrete Cross- sections
}

\author{
Cosmin G. Chiorean* \\ Technical University of Cluj-Napoca, Faculty of Civil Engineering, 15 C Daicoviciu Str., 400020, Cluj-Napoca, \\ Romania
}

\begin{abstract}
This paper presents an efficient numerical procedure for the rapid design of arbitrary-shaped composite steelconcrete cross-sections that are subjected to biaxial bending and axial force. The design procedure allows cross-sections to be designed by solving directly for the reinforcement required to provide a cross-section with adequate strength. The new numerical procedure developed in this paper shows very good stability in the presence of strain softening effect exhibited by the concrete in compression and tension and convergence stability is not affected by the shape of stress-strain relationships of concrete, the type and amount of reinforcements or the residual stress distribution in encased steel elements. A computer program was developed, aimed at obtaining the ultimate strength capacity and reinforcement required by reinforced and composite cross-sections subjected to combined biaxial bending and axial load. In order to illustrate the proposed method and its accuracy and efficiency, this program was used to study several representative examples, which have been studied previously by other researchers. The examples run and the comparisons made prove the effectiveness of the proposed numerical procedure.
\end{abstract}

Keywords: Rapid design, Interaction diagrams, Composite cross-sections, Residual stresses, Ultimate strength analysis, Biaxial bending.

\section{INTRODUCTION AND RESEARCH SIGNIFI- CANCE}

With the rapid advancement of computer technology, research works are currently in full swing to develop advanced nonlinear inelastic analysis methods of 3D frameworks, that involve accurate predictions of inelastic limit states up to or beyond structural collapse, and integrate them into the new and more rational advanced analysis and pushover design procedures. One of the key issues in developing such procedures represents the high accuracy and computational efficiency evaluation of elasto-plastic behavior of cross-sections subjected to axial force and biaxial bending moments $[1,2]$. The inelastic response of cross-sections can be represented by either momentcurvature diagrams for fixed values of axial force $(M-N-\phi)$ or interaction diagrams that express, at failure, the interaction between the axial load and bending moments about major and minor principal axes of the cross-section.

In recent years, some methods have been presented for the ultimate strength analysis of various concrete and composite steel-concrete sections. [3, 4, 6, 8, 10-16, 18]. These analyses are based on assumption that all structural and reinforcement parameters are specified and, under given

*Address correspondence to this author at the Technical University of ClujNapoca, Faculty of Civil Engineering, 15 C Daicoviciu Str., 400020, ClujNapoca, Romania; Tel/Fax.:+40 264 594967;

E-mail: cosmin.chiorean@mecon.utcluj.ro external loads either the cross section reaches its failure (ultimate strength analysis) or inelastic behavior of crosssection is revealed (moment-curvature analysis). On the other hand, procedures for solving directly for the reinforcement required to provide a cross-section with adequate strength (sectional design analysis) are essential in practical design avoiding the iterative approach of design generally emphasizing to establish that the ultimate strength of a section with known reinforcement is adequate.

Numerical procedures that allow the design of steel reinforcements for sections subjected to biaxial bending and axial force have been proposed in several papers [5, 7, 9, 17]. Dundar and Sahin [5] presented a procedure based on the Newton-Raphson method for dimensioning of arbitrarily shaped reinforced concrete sections, subjected to combined biaxial bending and axial compression. In their analysis the distribution of concrete stress is assumed to be rectangular according to Whitney's rectangular block. Rodrigues and Ochoa [7] extended this method for the more general cases when the concrete in compression is modelled using the explicit nonlinear stress-strain relationships. Chen et al. [9] proposed an iterative quasi-Newton procedure based on the Regula-Falsi numerical scheme for the rapid sectional design of short concrete-encased composite columns of arbitrary cross-section subjected to biaxial bending. This algorithm is limited to fully confined concrete. More recently, Pallares et al. [17], present a new iterative algorithm to design the steel reinforcement of concrete sections subjected to axial forces and biaxial bending. This method is based on the 
ultimate strains proposed by Eurocode-2 for sections under uniaxial bending and is limited also to fully confined concrete. For all these algorithms, problems of convergence may arise especially when starting or initial values (i.e. the parameters that define the strain profile over the cross-section) are not properly selected, and they may become unstable near the state of pure compression or tension. Moreover, all the above methods do not take into account the tension stiffening effect for concrete, strain-softening effect exhibited by the concrete in compression and residual stresses for encased steel section.

In this paper a new procedure based on Newton iterative method is proposed to design the required reinforcement for composite steel-concrete cross-sections subjected to axial force and biaxial bending moments. Moreover, procedure developed by the author in [18] for construction of moment capacity contours and interaction diagrams is enhanced by inclusion of concrete tension stiffening effect, multiple stress-strain relationships for concrete in compression, prestressed reinforced concrete sections and various distribution of residual stresses for encased steel section. Residual stresses in structural steel component are due to uneven cooling of component parts during the rolling process. However, only a few works available in the literature have addressed this effect on the carrying capacity of composite steel-concrete cross-sections. Studies of Virdi and Dowiing [20] and Shrabek and Mirza [19] indicate that the residual stresses can affect the strength of composite columns. For this reason, residual stresses were accounted for in encased steel sections used for the ultimate strength capacity evaluation of composite steel-concrete cross-sections and two types of residual stress patterns, EC2 and AISC-LRFD distribution, can be taken into account in the present formulation.

The method proposed herein, for design of crosssections, consists of computing the required reinforcement area $\left(A_{t o t}\right)$ supposing that all structural parameters are specified and, under given external loads, the cross section reaches its failure either in tension or compression. The problem is formulated by means of three equilibrium equations for the section. The condition of ultimate limit state is enforced by a compatibility equation imposing the maximum strain on the section to be equal to the limit strain of the corresponding material. These nonlinear equations are manipulated so that one of them is uncoupled and the Newton iterative strategy is applied only to the remaining coupled equilibrium equations in which total reinforcement steel area $A_{t o t}$, and the ultimate sectional curvatures $\phi_{x}$ and $\phi_{y}$ represent the unknowns.

The proposed approach is advantageous with respect to the existing ones [5, 7, 9, 17], in that the solution is obtained by solving just three coupled nonlinear equations and the convergence stability is not sensitive to the initial/starting values of the basic variables involved in the iterative process. Furthermore in the proposed approach only one variable $\left(A_{t o t}\right)$ requires an initial value to set up the iterative process, the iterative procedure starts with ultimate curvatures $\phi_{x}=0$, $\phi_{y}=0$. In most of the existing methods the convergence stability is governed by a good choice of the initial values of the basic variables which are not always simple to choose. This method, as compared to other iterative methods used in the solution of nonlinear equations for design of cross-sections, is very stable and convergence is very fast, the proposed iterative procedure has converged for many different problems in six to seven iterations, despite the quality of the initial value chosen for total required reinforcement area $A_{t o t}$.

Some studies [5] indicate that a negative value for reinforcement area $A_{t o t}$, that could be obtained as a solution of nonlinear equilibrium equations, corresponds to an unnecessarily big section and consequently the reinforcement is not necessary. This is a controversial issue, because both positive and negative values for the reinforcement could represent mathematical solution of the nonlinear equilibrium equations and consequently, convergence to a negative solution could not lead necessarily to the conclusion that the reinforcement is not required.

The stability and rapid convergence of the proposed approach are also due to the fact that the Jacobian's of the nonlinear system of equations is explicitly computed whereas in the methods proposed by Dundar and Sahin [5] and Rodrigues and Ochoa [7], the partial derivatives, involved in determination of the Jacobian matrix, can be only approximately expressed in terms of finite differences.

\section{MATHEMATICAL FORMULATION}

\subsection{Basic Assumptions and Constitutive Material Models}

Consider the cross-section subjected to the action of the external bending moments about both global axes and axial force as shown in Fig. (1). The cross-section may assume any shape with multiple polygonal or circular openings. It is assumed that plane section remains plane after deformation. This implies a perfect bond between the steel and concrete components of a composite concrete-steel cross section. Shear and torsional interaction effects are not accounted for in the concrete constitutive model.

Thus the resultant strain distribution corresponding to the curvatures about global axes $\Phi=\left\{\phi_{x}, \phi_{y}\right\}$ and the axial compressive strain $\varepsilon_{0}$ can be expressed at a generic point, in concrete matrix, fiber of structural steel or ordinary reinforced bars, of coordinates $(x, y)$ in a linear form as:

$\varepsilon=\varepsilon_{0}+\phi_{x} y+\phi_{y} x$

\section{Behavior of concrete in compression}

Two stress-strain relationships are taken into account, in the present investigation, to model the compressive behavior of concrete. The first constitutive relation [7] to model the concrete under compression is represented by a combination of a second-degree parabola (for ascending part) and a straight line (for descending part), Eq.(2), as depicted in Fig. (2a):

$$
f_{c}=\left\{\begin{array}{l}
f_{c}^{\prime \prime}\left(2 \frac{\varepsilon}{\varepsilon_{c 0}}-\frac{\varepsilon^{2}}{\varepsilon_{c 0}^{2}}\right), \quad \varepsilon \leq \varepsilon_{0} \\
f_{c}^{\prime \prime}\left(1-\gamma\left(\frac{\varepsilon-\varepsilon_{c 0}}{\varepsilon_{c u}-\varepsilon_{c 0}}\right)\right), \quad \varepsilon_{0}<\varepsilon
\end{array}\right.
$$




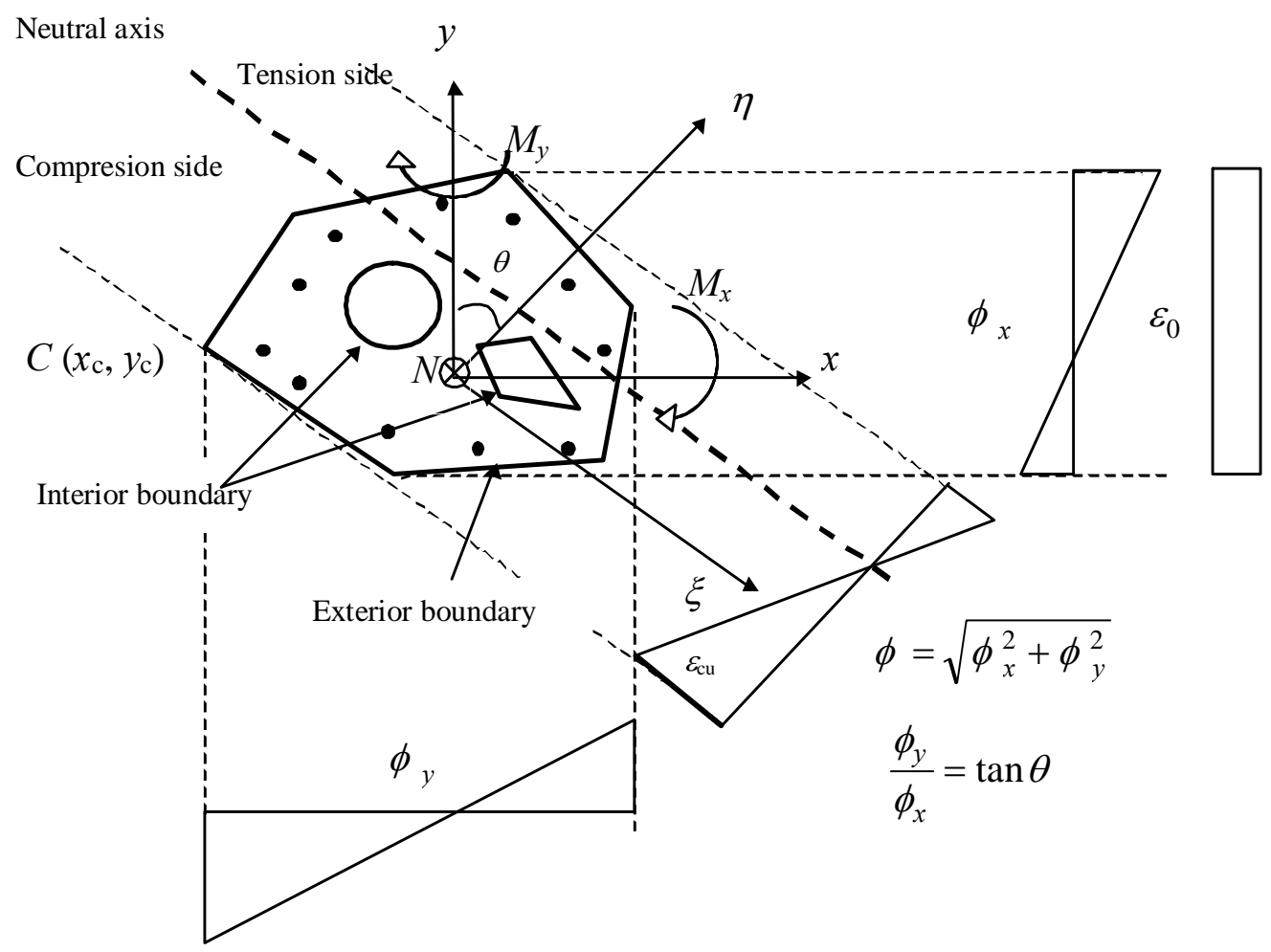

Fig. (1). Model of arbitrary composite cross-section.

(a)

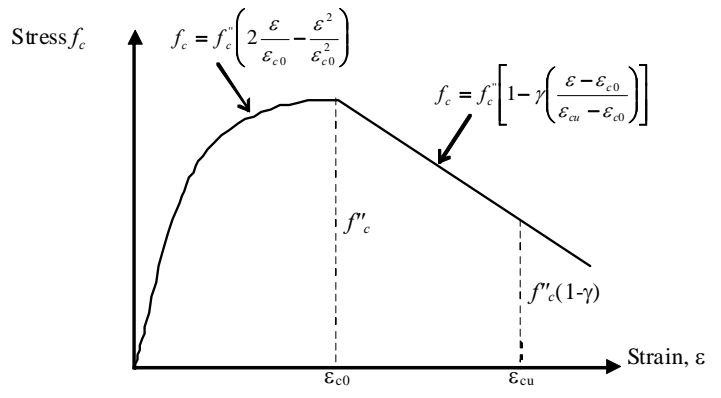

(b)

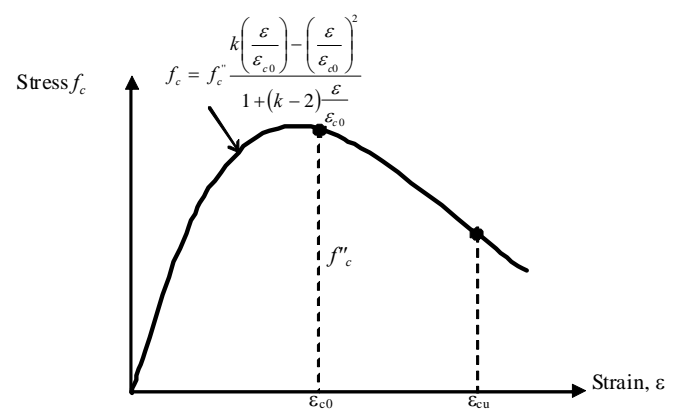

Fig. (2). Stress-strain relationships for concrete in compression: (a) combination of second-degree parabola and straight line; (b) EC2 stressstrain law.

where $\gamma$ represents the degree of confinement in the concrete and allows for the modelling of strain-softening, creep and confinement in concrete by simply varying the crushing strain $\varepsilon_{c 0}$, ultimate compressive strain $\varepsilon_{c u}$ and $\gamma$ respectively. The second constitutive relationship to model compressive behavior of concrete is the stress-strain law prescribed by Eurocode 2 [14], as depicted in Fig. (2b):

$$
f_{c}=f_{c}^{\prime \prime} \frac{k\left(\frac{\varepsilon}{\varepsilon_{c 0}}\right)-\left(\frac{\varepsilon}{\varepsilon_{c 0}}\right)^{2}}{1+(k-2) \frac{\varepsilon_{c}}{\varepsilon_{c 0}}}, \varepsilon \leq \varepsilon_{c u}
$$

where 


$$
k=1.1 E_{c} \frac{\varepsilon_{c 0}}{f_{c}^{\prime \prime}}
$$

and where $f_{c}$ " represents the concrete cylindrical compressive strength, $\varepsilon_{c 0}$ the crushing strain, $\varepsilon_{c u}$ the ultimate compressive strain and $E_{c}$ denotes the modulus of elasticity of concrete in compression.

\section{Behavior of concrete in tension}

Tension stiffening is an important phenomenon that should be included for an accurate analysis of sections under biaxial bending and axial load. Neglecting tension strength of concrete could lead to a loss in the smoothness of moment-curvature curves due to the sudden drop in stress from the cracking strength to zero at the onset cracking. In addition, tension stiffening results in a small change in peak strength, but this is usually negligible. The model to account for tension stiffening, developed by Vecchio \& Collins [21] is taken into account in the present investigation. The model of concrete in tension can be given in the following analytical form (Fig. 3):

$$
f_{t}=\left\{\begin{array}{l}
E_{t} \varepsilon, \varepsilon \leq \varepsilon_{c r} \\
\frac{\alpha_{1} \alpha_{2}^{2}}{1+\sqrt{500 \varepsilon}} f_{c r}, \varepsilon>\varepsilon_{c r}
\end{array}\right.
$$

where $E_{t}$ denotes the modulus of elasticity of concrete in tension; $f_{c r}$ represents the tensile strength of concrete; $\varepsilon_{c r}$ is the concrete cracking strain; $\alpha_{1}$ is a factor that takes into account the bounding characteristics of the reinforcement and $\alpha_{2}$ represents a factor that takes into account the effects of load duration and cyclic loads. As illustrated in Fig. (3) slow rate of tension softening is assumed for the concrete in tension.

\section{Behavior of steel reinforcement}

Elastic-perfect plastic stress-strain relationships, both in tension and in compression, are assumed for the structural steel and the conventional reinforcing bars. Residual stresses

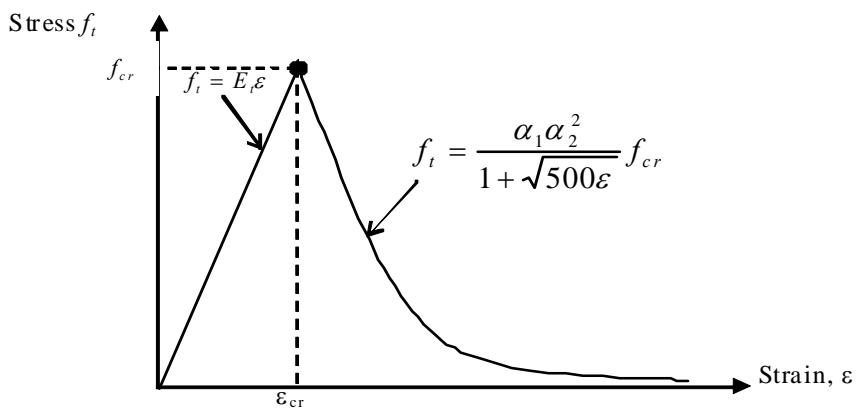

Fig. (3). Stress-strain relationships for concrete in tension.

may be incorporated in the analysis. The magnitude and distribution of residual stresses in hot-rolled members depend on the type of cross-section and manufacturing processes and different patterns are proposed. In the US, the residual stress is considered constant in the web although when the depth of a wide flange section is large, it varies more or less parabolically. Another possible residual stress pattern in the web is the one simplified by a linear variation as used in European calibration frames (Fig. 4).

Assuming that the residual strain can be linearized for individual zones in the steel section the total strain in a point can be computed as:

$\varepsilon=\varepsilon_{0}+\phi_{x} y+\phi_{y} x+\varepsilon_{r}$

where $\varepsilon_{\mathrm{r}}$ represents a linear residual strain field.

\subsection{Formulation of the proposed design procedure}

An iterative procedure based on Newton method is proposed to design a cross-section subjected to axial force $(N)$ and biaxial bending moments $\left(M_{x}, M_{y}\right)$. The method proposed herein consists of computing the required conventional reinforcement area $\left(A_{t o t}\right)$ supposing that all structural parameters are specified and, under given external loads, the cross section reach its failure either to maximum strains

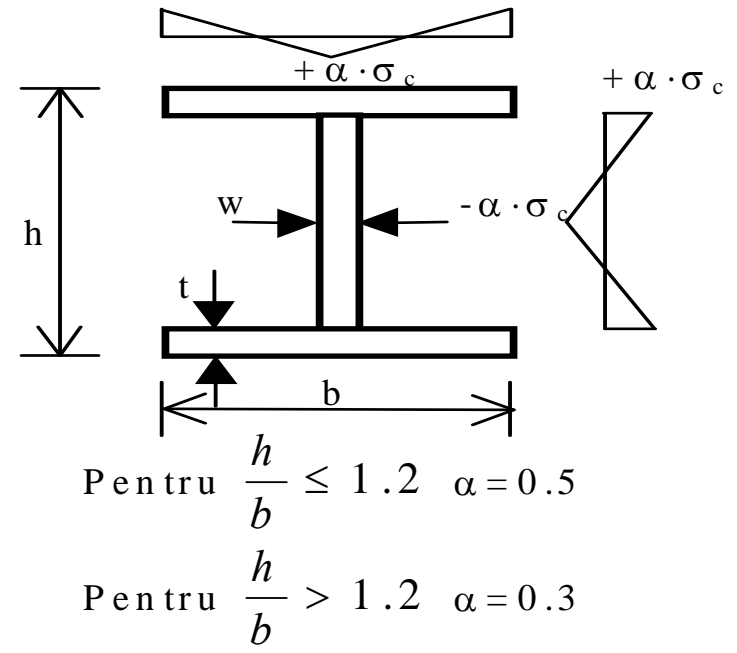

a) E C 3

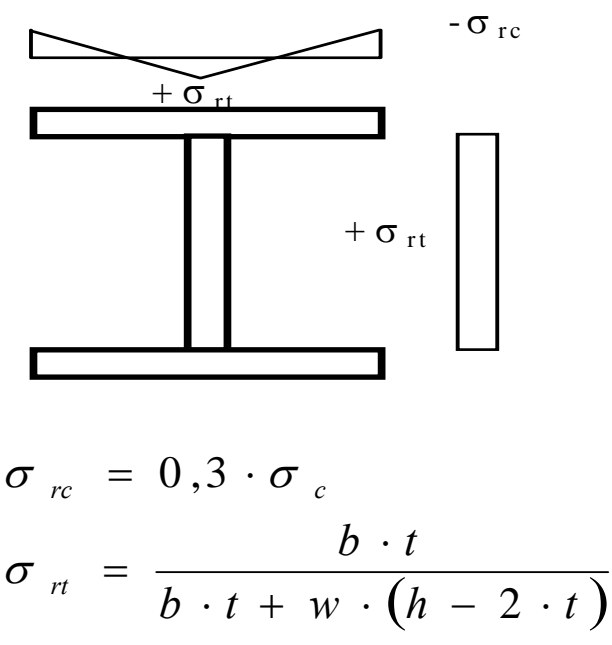

b) A IS C - L R F D

Fig. (4). Residual stress patterns. 
attained at the outer compressed point of the concrete section or to maximum strains attained in the most tensioned steel fibre.

Consider an irregular composite section as shown in Fig. (1) subjected to axial force and biaxial bending moments. The global $x, y$-axes of the cross section could have their origin either in the elastic or plastic centroid of the crosssection. The conventional reinforcement layout is given as percentage $\left(\alpha_{i}\right)$ of the total reinforcement steel area $\left(A_{t o t}\right)$ in each location. At ultimate strength capacity the equilibrium is satisfied when the external forces are equal to the internal ones and either in the most compressed or tensioned steel fibre the ultimate strain is attained. These conditions can be represented mathematically in terms of the following nonlinear system of equations as:

$$
\left\{\begin{array}{l}
\int_{A_{c s}} \sigma\left(\varepsilon\left(\varepsilon_{0}, \phi_{x}, \phi_{y}\right)\right) d A_{c s}+A_{t o t} \sum_{i=1}^{N_{r s}} \sigma\left(\varepsilon_{i}\left(\varepsilon_{0}, \phi_{x}, \phi_{y}\right)\right) \alpha_{i}-N=0 \\
\int_{A_{c s}} \sigma\left(\varepsilon\left(\varepsilon_{0}, \phi_{x}, \phi_{y}\right)\right) y d A_{c s}+A_{t o t} \sum_{i=1}^{N_{s s}} \sigma\left(\varepsilon_{i}\left(\varepsilon_{0}, \phi_{x}, \phi_{y}\right)\right) y_{i} \alpha_{i}-M_{x}=0(7) \\
\int_{A_{c s}} \sigma\left(\varepsilon\left(\varepsilon_{0}, \phi_{x}, \phi_{y}\right)\right) x d A_{c s}+A_{t o t} \sum_{i=1}^{N_{r s}} \sigma\left(\varepsilon_{i}\left(\varepsilon_{0}, \phi_{x}, \phi_{y}\right)\right) x_{i} \alpha_{i}-M_{y}=0 \\
\varepsilon_{0}+\phi_{x} y_{c}\left(\phi_{x}, \phi_{y}\right)+\phi_{y} x_{c}\left(\phi_{x}, \phi_{y}\right)-\varepsilon_{u}=0
\end{array}\right.
$$

in which $A_{t o t}, \varepsilon_{0}, \phi_{x}, \phi_{y}$ represent the unknowns, the surface integral is extended over concrete and structural steel areas $\left(A_{c s}\right), N_{r s}$ represents the number of conventional steel reinforcement bars. In the above equations the first three relations represent the basic equations of equilibrium for the axial load $N$ and the biaxial bending moments $M_{x}, M_{y}$ respectively. The last equation represents the ultimate strength capacity condition, that is, in the most compressed or most tensioned point the ultimate strain is attained; in this equation $x_{c}\left(\phi_{x}, \phi_{y}\right)$ and $y_{c}\left(\phi_{x}, \phi_{y}\right)$ represent the coordinates of the point in which this condition is imposed. The coordinates of the "constrained" point can be always determined for each inclination of the neutral axis defined by the parameters $\phi_{x}$ and $\phi_{y}$, and $\varepsilon_{u}$ represents the ultimate strain either in most compressed concrete point or in most tensioned steel fibre. The stresses in Equations (7) are calculated using the fiber strains and the constitutive relations.

For each inclination of the neutral axis defined by the parameters $\phi_{x}$ and $\phi_{y}$ the farthest point on the compression side (or the most tensioned reinforcement steel bar) is determined (i.e. the point with co-ordinates $x_{c}, y_{c}$ ). We assume that at this point the failure condition is met:

$\varepsilon_{0}+\phi_{x} y_{c}+\phi_{y} x_{c}=\varepsilon_{u}$

Hence, the axial strain $\varepsilon_{0}$ can be expressed as:

$\varepsilon_{0}=\varepsilon_{u}-\left(\phi_{x} y_{c}+\phi_{y} x_{c}\right)$

Taking into account Eq.(1), the resulting strain distribution corresponding to the curvatures $\phi_{x}$ and $\phi_{y}$ can be expressed in linear form as: $\varepsilon\left(\phi_{x}, \phi_{y}\right)=\varepsilon_{u}+\phi_{x}\left(y-y_{c}\right)+\phi_{y}\left(x-x_{c}\right)$

In this way, substituting the strain distribution given by the Eq.(10) in the basic equations of equilibrium, the unknown $\varepsilon_{0}$ together with the failure constraint equation can be eliminated from the nonlinear system (7). Thus, the nonlinear system of equations (7) is reduced to an only three basic equations of equilibrium as:

$$
\left\{\begin{array}{l}
\left.f_{1}\left(\phi_{x}, \phi_{y}, A_{t o t}\right) \equiv \int_{A_{c s}} \sigma\left(\varepsilon\left(\phi_{x}, \phi_{y}\right)\right) d A_{c s}+A_{t o t} \sum_{i=1}^{N_{t s}} \sigma\left(\varepsilon_{i}\left(\phi_{x}, \phi_{y}\right)\right)\right)_{i}-N=0 \\
f_{2}\left(\phi_{x}, \phi_{y}, A_{t o t}\right) \equiv \int_{A_{c s}} \sigma\left(\varepsilon\left(\phi_{x}, \phi_{y}\right)\right) y d A_{c s}+A_{t o t} \sum_{i=1}^{N_{r s}} \sigma\left(\varepsilon_{i}\left(\phi_{x}, \phi_{y}\right)\right) y_{i} \alpha_{i}-M_{x}=0 \\
\left.f_{3}\left(\phi_{x}, \phi_{y}, A_{t o t}\right) \equiv \int_{A_{c s}} \sigma\left(\varepsilon\left(\phi_{x}, \phi_{y}\right)\right)\right) x d A_{c s}+A_{t o t} \sum_{i=1}^{N_{r s}} \sigma\left(\varepsilon_{i}\left(\phi_{x}, \phi_{y}\right)\right) x_{i} \alpha_{i}-M_{y}=0
\end{array}\right.
$$

in which the unknowns, total reinforcement steel area $A_{t o t}$, and the ultimate sectional curvatures $\phi_{x}$ and $\phi_{y}$, can be obtained iteratively following the Newton method. In this respect, the system (13) can be rewritten in terms of non-linear system of equations in the following general form:

$\mathbf{F}(\mathbf{X})=\mathbf{f}^{\text {int }}-\mathbf{f}^{e x t}=\mathbf{0}$

where the external biaxial loading vector is:

$\mathbf{f}^{e x t}=\left[\begin{array}{lll}N & M_{x} & M_{y}\end{array}\right]^{T}$

and the internal forces vector, computed as function of the curvatures and total reinforcement steel area $A_{t o t}$, $\mathbf{X}=\left[\begin{array}{lll}\phi_{x} & \phi_{y} & A_{t o t}\end{array}\right]^{T}$ is:

$$
\mathbf{f}^{\text {int }}=\left[\begin{array}{l}
N^{\mathrm{int}}=\int_{A_{c s}} \sigma\left(\varepsilon\left(\phi_{x}, \phi_{y}\right)\right) d A_{c s}+A_{t o t} \sum_{i=1}^{N_{r s}} \sigma\left(\varepsilon_{i}\left(\phi_{x}, \phi_{y}\right)\right) x_{i} \\
M_{x}^{i n t}=\int_{A_{c s}} \sigma\left(\varepsilon\left(\phi_{x}, \phi_{y}\right)\right) y d A_{c s}+A_{t o t} \sum_{i=1}^{N_{r s}} \sigma\left(\varepsilon_{i}\left(\phi_{x}, \phi_{y}\right)\right) y_{i} \alpha_{i} \\
M_{y}^{\text {int }}=\int_{A_{c s}} \sigma\left(\varepsilon\left(\phi_{x}, \phi_{y}\right)\right) x d A_{c s}+A_{t o t} \sum_{i=1}^{N_{r s}} \sigma\left(\varepsilon_{i}\left(\phi_{x}, \phi_{y}\right)\right) x_{i} \alpha_{i}
\end{array}\right]
$$

According to the Newton iterative method, the iterative changes of unknowns vector $\mathbf{X}$ can be written as:

$$
\mathbf{X}^{k+1}=\mathbf{X}^{k}-\mathbf{F}^{\prime}\left(\mathbf{X}^{k}\right)^{-1} \mathbf{F}\left(\mathbf{X}^{k}\right), k \geq 0
$$

where $\mathbf{F}$ ' represents the Jacobian of the nonlinear system (13) and can be expressed as:

$$
\mathbf{F}^{\prime}=\left(\frac{\partial \mathbf{F}}{\partial \mathbf{X}}\right)=\left[\begin{array}{ccc}
\frac{\partial N^{\mathrm{int}}}{\partial \phi_{x}} & \frac{\partial N^{\mathrm{int}}}{\partial \phi_{y}} & \frac{\partial N^{\mathrm{int}}}{\partial A_{t o t}} \\
\frac{\partial M_{x}^{\text {int }}}{\partial \phi_{x}} & \frac{\partial M_{x}^{\text {int }}}{\partial \phi_{y}} & \frac{\partial M_{x}^{\text {int }}}{\partial A_{t o t}} \\
\frac{\partial M_{y}^{\text {int }}}{\partial \phi_{x}} & \frac{\partial M_{y}^{\text {int }}}{\partial \phi_{y}} & \frac{\partial M_{y}^{\text {int }}}{\partial A_{t o t}}
\end{array}\right]
$$



are:

Explicitly the expressions of the Jacobian's coefficients

$$
\begin{aligned}
& \frac{\partial N^{\mathrm{int}}}{\partial \phi_{x}}=\int_{A_{c s}} E_{t}\left(y-y_{c}\right) d A_{c s}+A_{t o t} \sum_{i=1}^{N_{r s}} E_{t i}\left(y_{i}-y_{c}\right) \alpha_{i} \\
& \frac{\partial N^{\mathrm{int}}}{\partial \phi_{y}}=\int_{A_{c s}} E_{t}\left(x-x_{c}\right) d A_{c s}+A_{t o t} \sum_{i=1}^{N_{r s}} E_{t i}\left(x_{i}-x_{c}\right) \alpha_{i} \\
& \frac{\partial N^{\mathrm{int}}}{\partial A_{t o t}}=\sum_{i=1}^{N_{r s}} \sigma\left(\varepsilon_{i}\right) \alpha_{i} \\
& \frac{\partial M_{x}^{\mathrm{int}}}{\partial \phi_{x}}=\int_{A_{c s}} E_{t} y\left(y-y_{c}\right) d A_{c s}+A_{t o t} \sum_{i=1}^{N_{r s}} E_{t i} y_{i}\left(y_{i}-y_{c}\right) \alpha_{i} \\
& \frac{\partial M_{x}^{\mathrm{int}}}{\partial \phi_{y}}=\int_{A_{c s}} E_{t} y\left(x-x_{c}\right) d A_{c s}+A_{t o t} \sum_{i=1}^{N_{r s}} E_{t i} y_{i}\left(x_{i}-x_{c}\right) \alpha_{i} \\
& \frac{\partial M_{x}^{\mathrm{int}}}{\partial A_{t o t}}=\sum_{i=1}^{N_{r s}} \sigma\left(\varepsilon_{i}\right) y_{i} \alpha_{i} \\
& \frac{\partial M_{y}^{\mathrm{int}}}{\partial \phi_{x}}=\int_{A_{c s}} E_{t} x\left(y-y_{c}\right) d A_{c s}+A_{t o t} \sum_{i=1}^{N_{r s}} E_{t i} x_{i}\left(y_{i}-y_{c}\right) \alpha_{i} \\
& \frac{\partial M_{y}^{\mathrm{int}}}{\partial \phi_{y}}=\int_{A_{c s}} E_{t} x\left(x-x_{c}\right) d A_{c s}+A_{t o t} \sum_{i=1}^{N_{r s}} E_{t i} x_{i}\left(x_{i}-x_{c}\right) \alpha_{i} \\
& \frac{\partial A_{t o t}^{\mathrm{int}}}{N_{r s}} \sigma\left(\varepsilon_{i}\right) x_{i} \alpha_{i} \\
& \sum_{i=1}
\end{aligned}
$$

These coefficients are expressed in terms of the tangent modulus of elasticity $E_{t}$, total reinforcement steel area $A_{t o t}$ and the coordinates $x_{c}, y_{c}$ of the "constrained" point. As already mentioned, during the iterative process, for each inclination of the neutral axis defined by the current curvatures, $\phi_{x}$ and $\phi_{y}$, the coordinates of the constrained point can be always determined and consequently the stiffness matrix coefficients can be evaluated. The iterative procedure starts with curvatures $\phi_{x}=0, \phi_{y}=0$. At the very first iteration, starting with the initial curvatures $\phi_{x}=0$ and $\phi_{y}=0$ the Jacobian $\mathbf{F}$ ' could become singular, because in this case the strain profile over the cross-section is uniform with maximum ultimate strain in compression or tension, which implies zero tangent modulus of elasticity. In this case one can simply start the iteration process with the secant modulus of elasticity in the evaluation of the tangent stiffness coefficients of the crosssection. For the next iterations an adaptive-descent algorithm [22] is applied in order to avoid the convergence difficulties related to negative-definition of the Jacobian matrix that can occur during the iterative process. Adaptive descent is a technique which switches to a secant matrix if convergence difficulties are encountered, and switches back to the full tangent as the solution convergences, resulting in the desired rapid convergence rate.

The initial approximation for $A_{\text {tot }}$ can be chosen by the user of the computer program, and represents the only parameter that controls the convergence process either to a positive or negative solution for the total reinforcements. It is important to note that from mathematical point of view both positive and negative values for the reinforcement could represent solutions of the nonlinear equilibrium equations. If the initial value of $A_{t o t}$ is taken to be $0.005 A_{g}$ (i.e. $A_{g}$ is gross cross-sectional area) it is observed that the iterative process described above has converged, to the positive solution, for many different problems in six to seven iterations. However, it was found that, sometimes, the iterative algorithm may converge to a negative value for the reinforcement steel area. In this case, using a trial and error process, the user has to restart the process with different initial values for total reinforcement steel area and searched for, in this way, the positive, and real solution of the problem. Alternatively, in order to avoid the convergence to a negative solution, during the iterative process, if the third variable $A_{t o t}$ has a negative value, this value is changed with a positive one and the iteration continue further with this value. With this procedure we have observed that the iterative process converges always to the positive solution, and the convergence stability is not affected by the quality of the initial approximation of the total reinforcement. On the other hand, if the iterative algorithm diverges this means that the section selected, subjected to axial force $(N)$ and biaxial bending moments $\left(M_{x}, M_{y}\right)$, is an unnecessarily big one and does not require any reinforcements.

The convergence criterion is expressed as a ratio of the norm of the out-of-balance force vector to the norm of the applied load. So the solution is assumed to have converged if:

$$
\frac{\sqrt{\mathbf{F}^{T} \mathbf{F}}}{\sqrt{\mathbf{f}^{e^{e x t T} \mathbf{f}^{e x t}}}} \leq T O L
$$

where $T O L$ is the specified computational tolerance, usually taken as $1 E-4$. As it was stated previously, the failure of the cross section can be controlled either by the most compressed concrete point or the most tensioned steel reinforcement bar. For a compression axial force, the iterative process is started with control in compression, whereas for a tension axial force the design of the cross-section is conducted starting the iterative process imposing the failure of the cross section in tension.

During the iterative process these controlled points are automatically interchanged. For instance, assuming that the current iterations are conducted with the most compressed point (Fig. 5) the strains profiles are defined by the same ultimate compressive strain and by different strains at the level of the most tensioned point. After the strains in the most tensioned point equal or exceed the tensile steel strain at failure, the control point becomes the most tensioned point, and the process continues similarly, but with the coordinates of this point and associated ultimate steel strain. Fig. (5) presents different types of strain profiles during this process, defined by the either ultimate compressive strain $(1,2, \ldots)$ or by the ultimate steel strain $(1,2, \ldots)$. Fig. (6) shows a simplified flowchart of this analysis algorithm. 


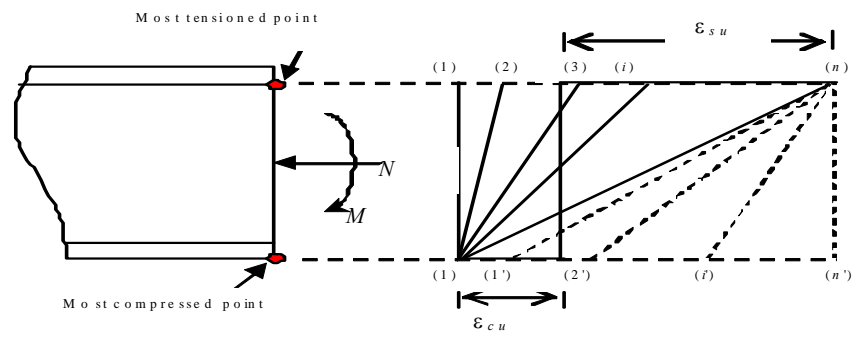

Fig. (5). Strains profile at failure.

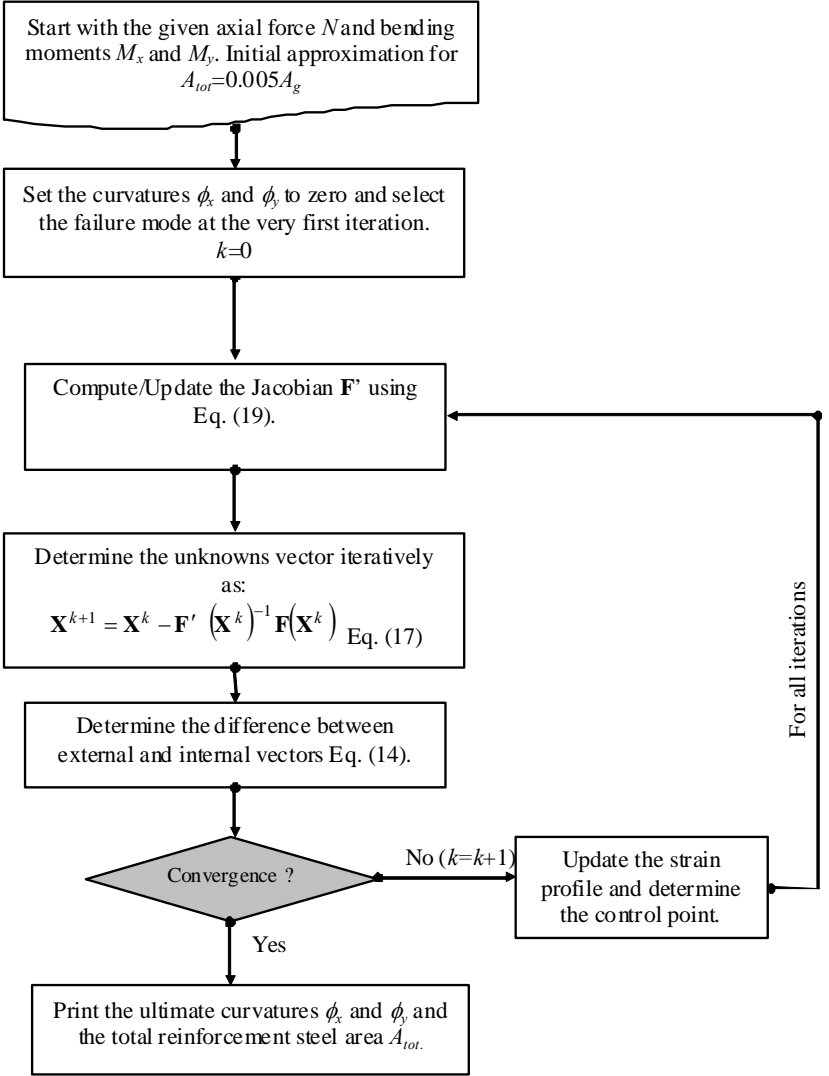

Fig. (6). Flowchart for design procedure.

\subsection{Evaluation of Tangent Stiffness and Stress Resultant}

Based on Green's theorem, the integration of the stress resultant and stiffness coefficients over the cross-section will be transformed into line integrals along the perimeter of the cross-section. For this purpose, it is necessary to transform the variables first, so that the stress field is uniform in a particular direction, given by the current position of the neutral axis [23]. This is achieved by rotating the reference axes $x, y$ to $\xi, \eta$ oriented parallel to and perpendicular to the neutral axis, respectively (Fig. 1) such that:

$$
\left\{\begin{array}{l}
x=\xi \cos \theta+\eta \sin \theta \\
y=-\xi \sin \theta+\eta \cos \theta
\end{array}\right.
$$

where $\tan \theta=\phi_{y} / \phi_{x}$. Based on this transformation, the internal forces carried by the concrete and structural steel areas $\left(A_{c s}\right)$ can be obtained by the following expressions:

$$
\begin{aligned}
& N_{\text {int }}=\iint_{A_{s}} \sigma(x, y) d x d y=\iint_{A_{s c}} \sigma(\eta) d \xi d \eta \\
& M_{x, \text { int }}=\iint_{A_{s}} \sigma(x, y) y d x d y=\iint_{A_{s s}} \sigma(\eta)(-\xi \sin \theta+\eta \cos \theta) d \xi d \eta=M_{\xi, \text { int }} \cos \theta-M_{\eta, \text { int }} \sin \theta \\
& M_{y, \text { int }}=\iint_{A_{s s}} \sigma(x, y) x d x d y=\iint_{A_{s}} \sigma(\eta)(\xi \cos \theta+\eta \sin \theta) d \xi d \eta=M_{\xi, \text { int }} \sin \theta-M_{\eta, \text { int }} \cos \theta
\end{aligned}
$$

where $N_{i n t}, M_{\xi, \text { int }}$ and $M_{\eta, \text { int }}$ are the internal axial force and bending moments about the $\xi$ and $\eta$ axis respectively and can be obtained by the following expressions:

$$
\begin{aligned}
& M_{\xi, \text { int }}=\iint_{A_{c s}} \sigma(\eta) \eta d \xi d \eta=\oint_{L} \sigma(\eta) \xi \eta d \eta \\
& M_{\eta, \text { int }}=\iint_{A_{c s}} \sigma(\eta) \xi d \xi d \eta=\frac{1}{2} \oint_{L} \sigma(\eta) \xi^{2} d \eta \\
& N_{\text {int }}=\iint_{A_{c s}} \sigma(\eta) d \xi d \eta=\oint_{L} \sigma(\eta) \xi d \xi d \eta
\end{aligned}
$$

The tangent stiffness matrix coefficients are computed in the same way [18]. As the integration area contour is approximated by a polygon, the integral over the perimeter $L$, can be obtained by decomposing this integral side by side along the perimeter:

$$
\oint_{L} h(\eta) \xi^{p} d \eta=\sum_{i=1}^{n L} \int_{\eta_{i}}^{\eta_{i+1}} h(\eta) \xi^{p} d \eta
$$

where $n L$ is the number of sides that forms the integration area. The sides are defined by the $\xi \eta$ co-ordinates of the endpoints as shown in Fig. (1). When the integration area is a circle with radius $R$, the integral over the perimeter $L$ can be obtained by decomposing this integral as:

$$
\oint_{L} h(\eta) \xi^{p} d \eta=\int_{-R}^{R} h(\eta)\left(R^{2}-\eta^{2}\right)^{p / 2} d \eta+(-1)^{p} \int_{R}^{-R} h(\eta)\left(R^{2}-\eta^{2}\right)^{p / 2} d \eta
$$

This leads to a significant saving in imputing the data to describe the circular shapes, without the need to decompose the circular shapes as a series of straight lines and approximate the correct solution when circular boundaries are involved. In order to perform the integral on a determined side of the contour $\left(L_{i}\right)$, polygonal or circular, of the integration area, an adaptive interpolatory Gauss-Lobatto method is used [18].

The conventional steel reinforcements are assumed to be discrete points with effective area, co-ordinates and stresses. To avoid double counting of the concrete area that is displaced by the steel bars, the concrete stress at the centroid of the steel bars is subtracted from the reinforcement bar force. In order to identify the various regions in a complex crosssection with different material properties each region with assigned material properties is treated separately [16]. In this way, any composite cross-section with different material properties can be integrated without difficulties.

The magnitude and distribution of residual stresses in hot-rolled members depend on the type of cross section and manufacturing processes and different patterns are proposed. 
In the US, the residual stress is considered constant in the web although, when the depth of a wide flange section is large, it varies more or less parabolically. Another possible residual stress pattern in the web is the one simplified by a linear variation as used in European calibration frames. The effect of residual stresses may be included in the analysis providing that the residual stress can be linearized for individual zones in the steel section associated to variations of residual stresses throghout the height of cross-section. For instance assuming the EC3 distribution of residual stresses the cross-section has to be divided in six regions as depicted in Fig. (7). In this way for each region the total strain in can be expressed as:

$$
\varepsilon=\varepsilon_{0}+\phi_{x} \cdot y+\phi_{y} \cdot x+\varepsilon_{r}
$$

where $\varepsilon_{\mathrm{r}}$ represents a linear residual strain field which can be expressed for each particularly region as:

$\varepsilon_{r}=a_{1}+a_{2} x+a_{3} y$

Next, the integration of the stress resultant and stiffness coefficients over the steel cross-section will be transformed into line integrals along the perimeter of the cross-section as already described, but in this case the reference axes are rotated for each region using the following value for angle $\theta$ :

$$
\tan \theta=\frac{\phi_{y}+a_{2}}{\phi_{x}+a_{3}}
$$

\section{COMPUTATIONAL EXAMPLES}

Based on the analysis algorithm just described, a computer program ASEP has been developed to study the biaxial strength behavior of arbitrary composite concrete-steel cross sections. It combines the analysis routine with a graphic routine to display the final results. The computational engine was written using Compaq Visual Fortran. The graphical interface was created using Microsoft Visual Basic 6. Dynamic Link Libraries (DLL) are used to communicate between interface and engine. The many options included make it a user friendly computer program. The graphical interface allows for easy generation of cross-sectional shapes and reinforcement bars, graphical representation of the data, and plotting of the complete stress field over the cross-section, instantaneous position of neutral axis, interaction and moment capacity contour diagrams, etc.
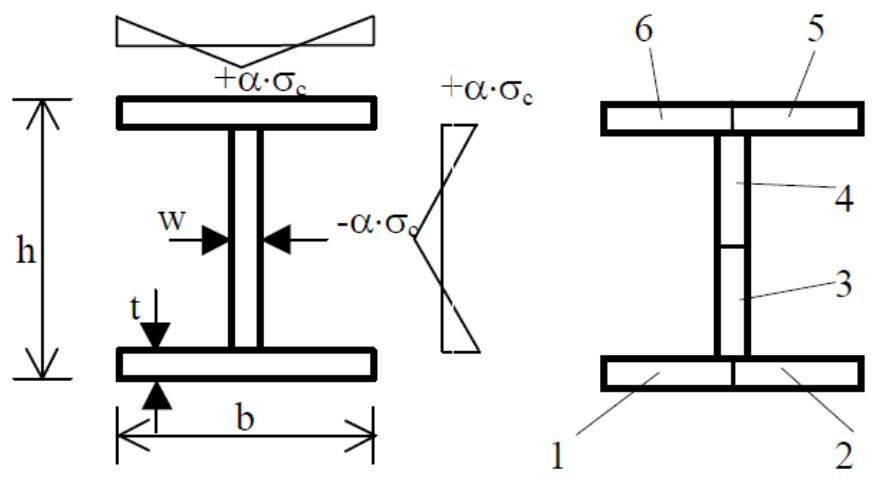

Fig. (7). Division of structural steel. Incorporation of residual stresses.
The accuracy and computational advantages of the numerical procedure developed here has been evaluated using several selected benchmark problems analyzed previously by other researchers using different numerical methods. Furthermore new parametric studies and computational examples are given in order to demonstrate the effectiveness of the ultimate strength capacity evaluation procedure described in the previous paper published by the author [18].

\subsection{Example 1: Composite Steel-concrete Cross-section with Arbitrary Shape}

The composite steel-concrete cross-section depicted in Fig. (8), consists of the concrete matrix, fifteen reinforcement bars of diameter $18 \mathrm{~mm}$, a structural steel element and a circular opening. Characteristic strengths for concrete, structural steel and reinforcement bars are $f^{\prime \prime}{ }_{c}=30 \mathrm{Mpa}$, $f_{s t}=355 \mathrm{Mpa}$ and $f_{s}=460 \mathrm{Mpa}$, respectively. These characteristic strengths are reduced by dividing them with the corresponding safety factors $\gamma_{c}=1.50, \gamma_{s t}=1.10$ and $\gamma_{s}=1.15$. The stress-strain curve for concrete which consists of a parabolic and linear-horizontal- part was used in the calculation, with the crushing strain $\varepsilon_{0}=0.002$ and ultimate strain $\varepsilon_{c u}=0.0035$. The Young modulus for all steel sections was $200 \mathrm{GPa}$ while the maximum strain was $\varepsilon_{u}= \pm 1 \%$. A bi-linear elasto-perfect plastic stress-strain relationship for the reinforcement bars and structural steel, both in tension and in compression, is assumed. The strain softening effect for the concrete in compression is taken into account, in the present approach, through the parameter $\gamma$. This is an example proposed and analyzed by Chen et al. [9] and later studied by Charalmpakis and Koumousis [16], Rosati et.al [13] and others.

In order to verify the stability of the proposed method a series of analyses have been conducted to determine the influence of confinement, stress-strain relationships for concrete in compression and residual stresses for encased structural steel element over ultimate strength capacity of the cross-section.

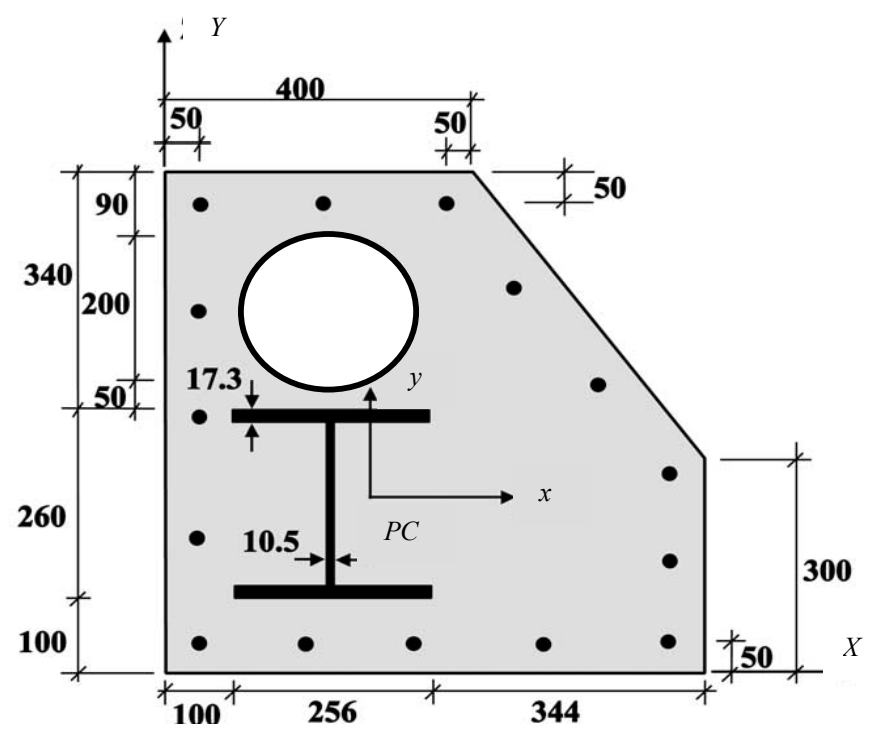

Fig. (8). Example 1. Composite steel-concrete cross-section. 
The effects of confinement in the concrete were investigated for different values of degree of confinement. As it can be seen in Fig. (9) by reducing the confinement in the concrete the interaction curves indicate lower capacities and the non-convexity of the diagrams is more pronounced. The bending moments are computed about the geometric centroidal axes for a compressive axial force $N=10000 \mathrm{kN}$ and a very restrictive equilibrium tolerance has been considered, Tol=1E-10. It is important to underline that, for all points, represented in the moment capacity diagrams depicted in Figure 9, the strain field fulfils the ultimate value for concrete in compression and satisfies the equilibrium conditions. This numerical test illustrates the efficiency of the proposed approach and convergence stability.

Fig. (10) shows the moment capacity contours with different values of axial compressive load and different stressstrain relationships for concrete in compression. In the model described by the Eq. 2 the strain softening effect for the concrete in compression is taken into account considering the parameter $\gamma=0.15$. As it can be seen the EC2 model (given by the Eq. 3) indicates lower capacity of cross section and also non-convexity of diagrams. These diagrams are computed about the geometric centroidal axes of the crosssection and no convergence difficulties have been encountered.

Let us consider this cross-section subjected to biaxial bending to carry the following design loads: $N=4120 \mathrm{kN}$, $M_{x}=210.5 \mathrm{kN}$ and $M_{y}=863.5 \mathrm{kNm}$. The distribution of the steel reinforcing bars is shown in Fig. (10), and we consider that all rebars have the same diameter. The procedure described at section 2.2 is used to find the required total steel reinforcement for the cross-section to achieve an adequate resistance for the design loads. As shown in Table $\mathbf{1}$ the iterative process of design was started with $\phi_{x}=0$ and $\phi_{y}=0$, and $A_{\text {tot }}=0.005 A_{\mathrm{g}}=215 \mathrm{~cm}^{2}$. The equilibrium tolerance has been taken as $1 E$-4. After only five iterations, the total area required of the rebars was found to be $A_{t o t}=34.347 \mathrm{~cm}^{2}$. Consequently, the required diameter of the selected rebar is $\Phi_{\text {req }}=2 \sqrt{\frac{A_{\text {tot }}}{N_{b} \pi}}=1.71 \mathrm{~cm}$ which compare very well with the required bar diameter reported by Chen et.al. [9], $\Phi_{\text {req }}=1.78 \mathrm{~cm}$. Reinforcement bars of diameter $18 \mathrm{~mm}$ are thus suitable for this cross-section. In the above computational example, the axial force and bending moments are

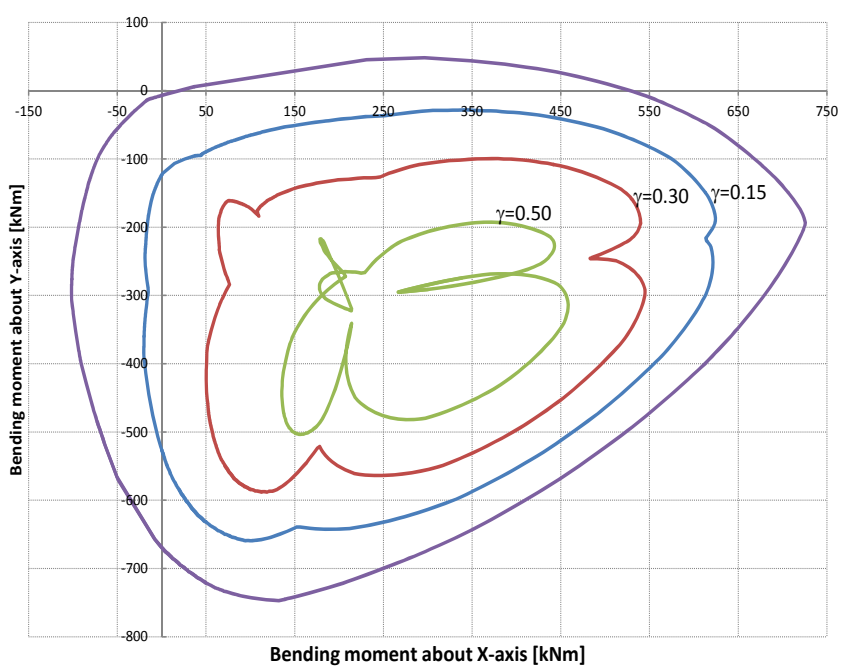

Fig. (9). Moment capacity contours with compressive axial load $N=10000 \mathrm{kN}$ for different values of degree of confinement.

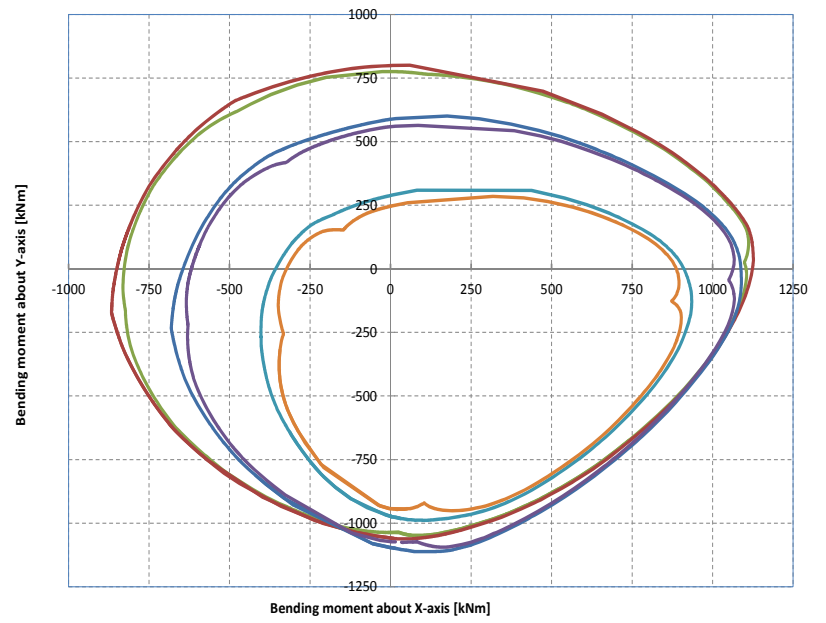

Fig. (10). Moment capacity contours with different values of axial compressive load and different stress-strain relationships of concrete.

represented about the plastic centroidal axes of the crosssection. When the design loads are represented about the geometric centroid the total area required of the rebars was

Table 1. Example 1. Main Parameters Involved in the Design of Composite Steel-concrete Section

\begin{tabular}{|c|c|c|c|c|}
\hline Iteration & $\phi_{x}$ & $\phi_{y}$ & $\boldsymbol{A}_{\text {tot }}\left[\mathbf{c m}^{2}\right]$ & Error (Eq. 18) \\
\hline \hline Initial & 0.000 & 0.000 & $0.005 A_{g}=215$ & 1.000 \\
\hline 1 & $2.977 \mathrm{E}-5$ & $7.197 \mathrm{E}-5$ & 144.835 & 1.08254 \\
\hline 2 & $2.9187 \mathrm{E}-5$ & $7.9279 \mathrm{E}-5$ & 20.168 & 0.8347 \\
\hline 3 & $2.9093 \mathrm{E}-5$ & $8.6250 \mathrm{E}-5$ & 33.351 & 0.1060 \\
\hline 4 & $2.9003 \mathrm{E}-5$ & $8.5837 \mathrm{E}-5$ & 34.350 & 0.010026 \\
\hline 5 & $2.9000 \mathrm{E}-5$ & $8.5850 \mathrm{E}-5$ & 34.347 & 0.000082 \\
\hline
\end{tabular}


found to be $A_{t o t}=15.674 \mathrm{~cm}^{2}$. This result has been obtained after only six iterations. For this case the reference [9] does not present comparative results.

The effect of residual stresses over strength capacity of cross-section is presented in Table 2 and Fig. (11). Table 2 presents the variations of total reinforcement area considering different values of compressive axial load and two types of residual stress patterns, EC3 and AISC-LRFD respec- tively, for structural steel element. As it can be seen the presence of residual stresses increases the total reinforcement steel area as axial compressive load is increased. Fig. (11) presents the moment capacity contours for different values of axial compressive load with and without the presence of residual stresses. The bending moments are computed about the plastic centroidal axes for different values of compressive axial force $(\mathrm{N}=4120,6000 \mathrm{kN}, 8000 \mathrm{kN}, 10000 \mathrm{kN})$. The
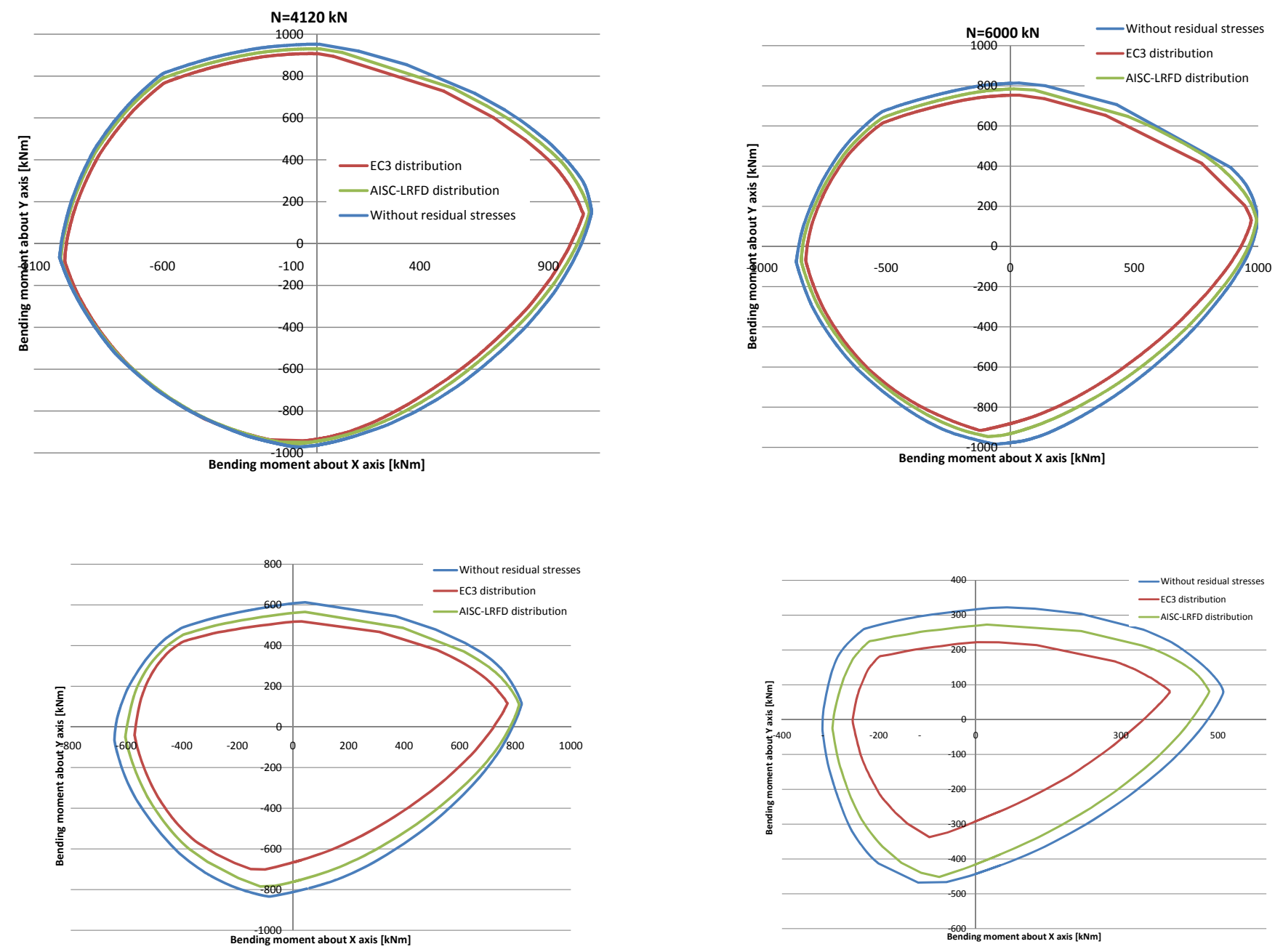

Fig. (11). Moment capacity contours with different values of compressive axial load and different residual stress patterns for encased steel section.

Table 2. Example 1: Influence of Residual Stresses Over Total Reinforcement Steel Area $\left(M_{x}=210.5 \mathrm{kN}\right.$ and $\left.M_{y}=863.5 \mathrm{kNm}\right)$

\begin{tabular}{|c|c|c|c|}
\hline $\mathbf{N}[\mathbf{k N}]$ & $\mathbf{A}_{\text {tot }}\left[\mathbf{c m}^{2}\right]$ (Without Residual Stresses) & $\mathbf{A}_{\text {tot }}\left[\mathbf{c m}^{2}\right]$ (EC3 Distribution) & $\mathbf{A}_{\text {tot }}$ [cm ${ }^{2}$ (AISC-LRFD Distribution) \\
\hline \hline 1000 & 58.82 & 58.28 & 57.69 \\
\hline 3000 & 41.55 & 42.47 & 32.18 \\
\hline 5000 & 31.19 & 41.85 & 42.37 \\
\hline 6000 & 33.41 & 50.83 & 71.25 \\
\hline 8000 & 61.01 & 86.60 & 93.57 \\
\hline 9000 & 84.16 & 110.38 & 118.83 \\
\hline 10000 & 110.43 & 136.37 & \\
\hline
\end{tabular}


strain softening effect for the concrete in compression is not taken into account $(\gamma=0)$. As it can be seen the residual stresses indicates lower capacity of cross section, and this effect is more pronounced as axial load increases.

\subsection{Example 2: Rectangular Composite Steel-concrete Section. Influence of Residual Stresses}

In order to evaluate the effects of residual stresses over ultimate strength capacity, of composite steel-concrete cross section, the moment-capacity contours diagrams are determined for a very common composite cross- section under biaxial loading: rectangular cross-section with symmetrically placed structural steel. The cross-section consists of a concrete core and a symmetrically placed USA wide flange section W12x120 (Fig. 12).

Characteristic strength for concrete in compression is $f^{\prime \prime}{ }_{c}=20 \mathrm{MPa}$ and the stress-strain curve which consists of a parabolic and linear part was used in the calculation (Eq.2), with crushing strain $\varepsilon_{0}=0.002$, ultimate strain $\varepsilon_{c u}=0.0035$. The strain softening of concrete is taken into account with $\gamma=0.15$. The Young modulus for encased structural steel and reinforcements is $200 \mathrm{GPa}$. A bi-linear elasto-perfect plastic
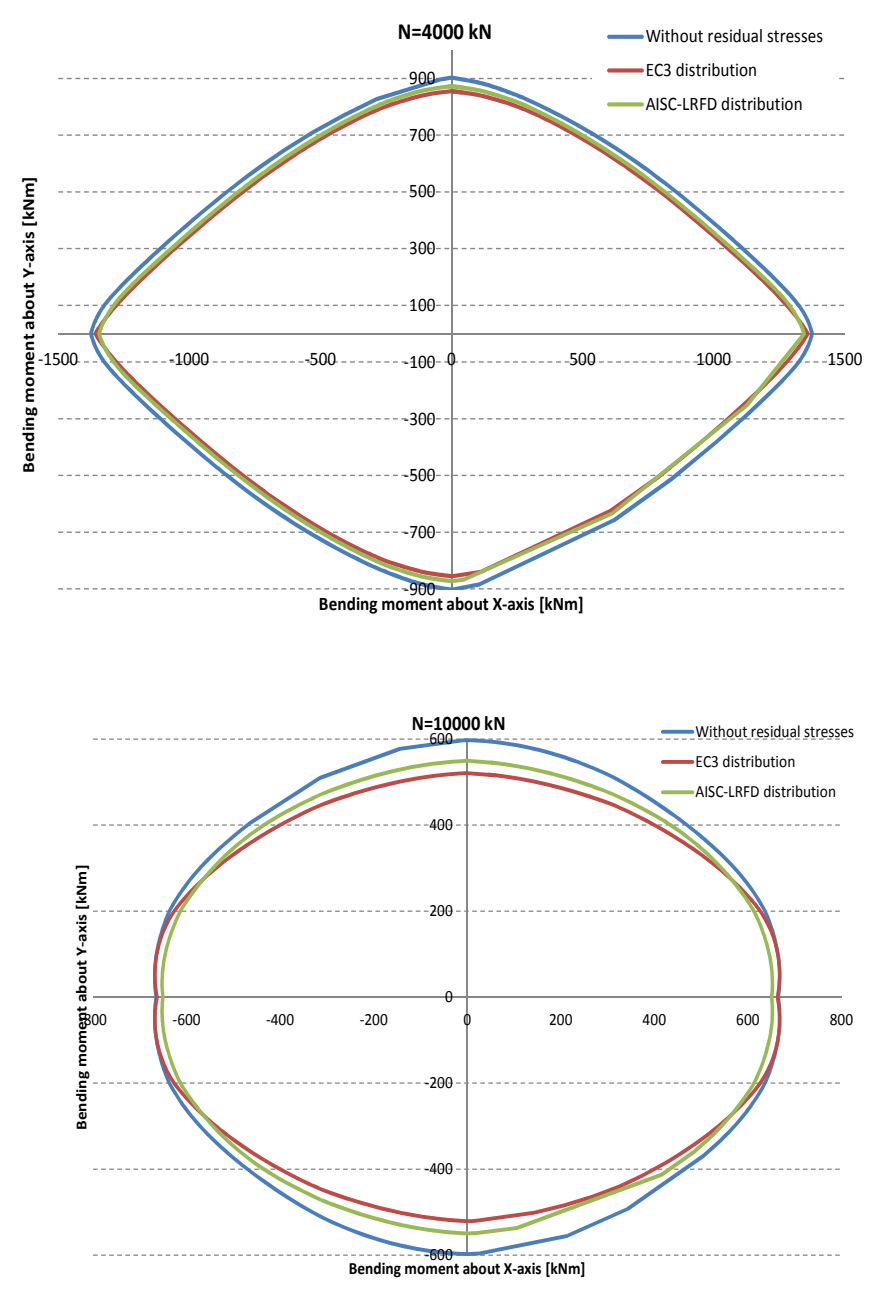

stress-strain relationship for the reinforcement bars and structural steel, both in tension and in compression, is assumed with the yield strength $f_{y}=300 \mathrm{MPa}$.

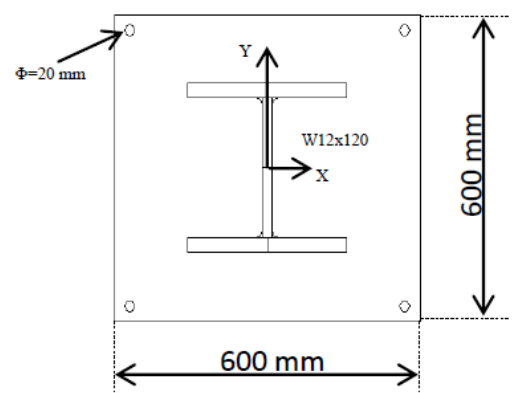

Fig. (12). Rectangular composite steel-concrete cross-section.

Fig. (13) presents the moment capacity contours for different values of axial compressive load with and without the presence of residual stresses. As it can be seen the residual stresses indicates lower capacity of cross section, and this effect is more pronounced as axial load increases especially in the case of EC3 distribution for residual stresses.
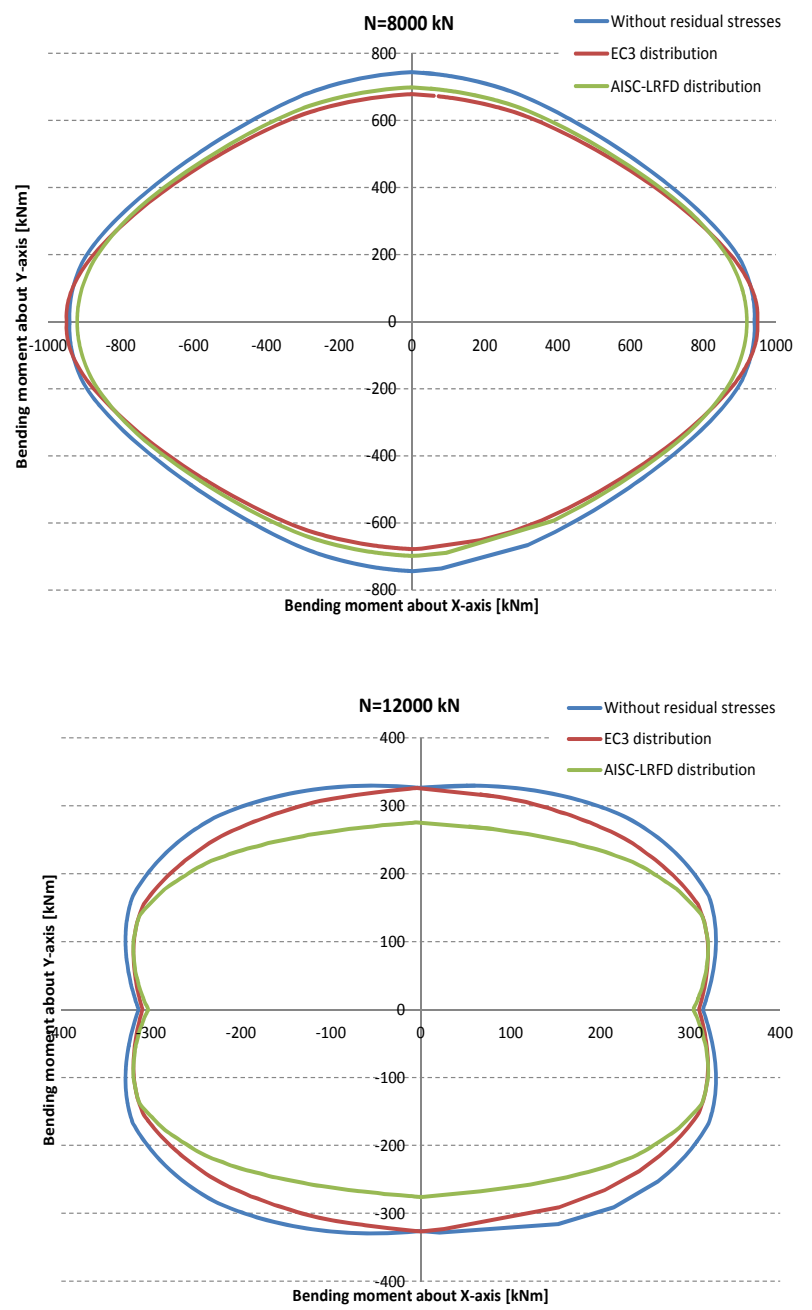

Fig. (13). Moment capacity contours with different values of axial compressive load and different residual stress patterns for encased steel section. 


\subsection{Example 3: Reinforced Concrete Box Cross-section}

The box cross-section, depicted in Fig. (14a), consists of the concrete matrix and sixteen reinforcement bars, all rebars having the same diameter. This section is subjected to the following design loads: $N=2541.7 \mathrm{kN}, M_{x}=645.6 \mathrm{kNm}$, and $M_{y}=322.8 \mathrm{kNm}$. Characteristic strengths for concrete and reinforcement bars are: $f_{c}^{\prime \prime}=23.443 \mathrm{MPa}, f_{y}=413.69 \mathrm{MPa}$ respectively.

The stress-strain curve for concrete which consists of a parabolic and linear-descending- part was used in the calculation, with the crushing strain $\varepsilon_{0}=0.002$ and ultimate strain $\varepsilon_{c u}=0.0038$. The Young modulus for reinforcing bars was 200GPa while the maximum strain was $\varepsilon_{u}= \pm 1 \%$. A bi-linear elasto-perfect plastic stress-strain relationship for the reinforcement bars, both in tension and in compression, is assumed. The strain softening effect for the concrete in compression is taken into account, in the present approach, through the parameter $\gamma$. This problem was also solved by Rodrigues \& Ochoa [7]. The procedure described at section 2.2 is used to find the required total steel reinforcement for the cross-section to achieve an adequate resistance for the above mentioned design loads. The strain softening parameter $\gamma=0.15$ for the concrete in compression has been considered in analysis.

As shown in Table 3 the iterative process of design was started with $\phi_{x}=0$ and $\phi_{y}=0$, and $A_{\text {tot }}=0.005 A_{\mathrm{g}}=12.25 \mathrm{~cm}^{2}$. The equilibrium tolerance has been taken as $1 E-4$. After only six iterations, the total area required of the rebars was found to be $A_{t o t}=40.586 \mathrm{~cm}^{2}$. This means that the area required of the selected rebar is $2.536 \mathrm{~cm}^{2}$ which compare very well with the required area, $2.535 \mathrm{~cm}^{2}$, reported by Rodrigues \&
Ochoa [7]. Fig. (14.b) shows the plastic status of the crosssection associated to the equilibrium between external design loads and internal forces with the total reinforcing area obtained after six iterations. If the effect of tension stiffening is taken into account, considering resistance of tensioned concrete with $E_{t}=33000 \mathrm{MPa}$, tensile strength $f_{c r}=0.234 \mathrm{MPa}$, concrete cracking strain $\varepsilon_{c r}=0.000071$ and $\alpha_{1}=1, \alpha_{2}=0.75$, the total area required was found, in only five iterations, to be $A_{\text {tot }}=37.875 \mathrm{~cm}^{2}$ which is with $7 \%$ smaller than the case in which tension stiffening effect was ignored. For this case the reference [7] does not present comparative results. The influence of the initial values assumed for total reinforcement area over convergence process is illustrated in Table 4.

As it can be seen, even under a very restrictive tolerance (Tol=1E-10) and with initial values chosen very far from the solution, the iterative procedure converge without difficulties in a few iterations. Moreover the number of iterations is not influenced by the quality of the initial approximation chosen for total reinforcement area.

Fig. (15) shows the corresponding interaction curves for both $M_{\mathrm{x}}$ and $M_{\mathrm{y}}$ of this section for $\alpha=26.56^{\circ}\left(M_{y} / M_{x}=\tan (\alpha)\right)$ with and without tension stiffening effect. Fig. (16) shows the moment capacity diagrams for $N=2541.7 \mathrm{kN}$ considering different levels of confinement. Rebars of diameter $3 / 4$ " $11.90 \mathrm{~cm}$ has been considered in these analyses. As it can be seen, by reducing the confinement in the concrete $(\gamma=0.15,0.50)$ the interaction curves indicate lower capacities (Fig. 16) and the non-convexity of the diagrams is more pronounced, and also, near the compressive axial load capacity multiple solutions exist in the $N-M$ space when the strain softening is modelled, $\gamma=0.15$ (Fig. 15). For all these points the strain field fulfils the ultimate value for concrete in com-

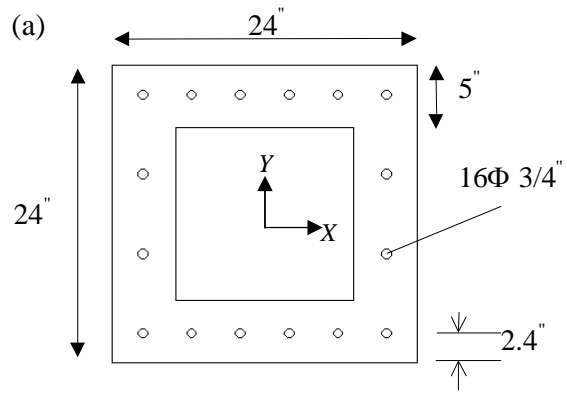

(b)

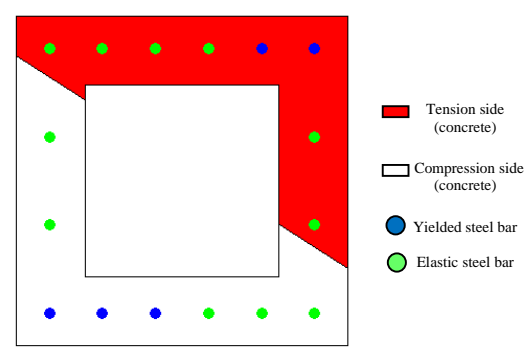

Fig. (14). Example 3. (a) Biaxially loaded box cross-section; (b) Plastic status of section under design loads and $A_{\text {tot }}=40.586 \mathrm{~cm}^{2}$.

Table 3. Example 3: Main Parameters Involved in the Iterative Process

\begin{tabular}{|c|c|c|c|c|}
\hline Iteration & $\phi_{\mathbf{x}}$ & $\phi_{\mathbf{y}}$ & $\mathbf{A}_{\text {tot }}\left[\mathbf{c m}^{2}\right]$ & Error $\mathbf{( E q . ~ 2 0 )}$ \\
\hline \hline Initial & 0.000 & 0.000 & $0.005 \mathrm{~A}_{\mathrm{g}}=12.25$ & 1.000 \\
\hline 1 & $1.089 \mathrm{E}-4$ & $5.576 \mathrm{E}-5$ & 115.41 & 1.000146 \\
\hline 2 & $6.426 \mathrm{E}-5$ & $5.264 \mathrm{E}-5$ & 30.816 & 0.599621 \\
\hline 3 & $7.102 \mathrm{E}-5$ & $4.550 \mathrm{E}-5$ & 39.682 & 0.173854 \\
\hline 4 & $7.084 \mathrm{E}-5$ & $4.559 \mathrm{E}-5$ & 40.556 & 0.007475 \\
\hline 5 & $7.0834 \mathrm{E}-5$ & $4.5583 \mathrm{E}-5$ & 40.585 & 0.000266 \\
\hline 6 & $7.08345 \mathrm{E}-5$ & $4.5583 \mathrm{E}-5$ & 40.586 & 0.00000856 \\
\hline
\end{tabular}


pression and also the equilibrium conditions.

The effects of confinement and creep in the concrete over the total steel reinforcing area are presented in Tables $\mathbf{5}$ and 6. The section is subjected to the same design loads as in the previously computation. As it can be seen in Table 5 by reducing the confinement in the concrete (i.e. by increasing the value of $\gamma$ in descending branch of compressed concrete stress-strain curve) the total reinforcing area increases. No convergence problems have been experienced by the proposed approach, a maximum of seven iterations have been required to determine the reinforcement area for the case when $\gamma=0.5$. The effect of creep of the concrete has been investigated by varying the value of crushing strain $\varepsilon_{c 0}$. The ultimate strain in the compressed concrete is considered as: $\varepsilon_{c u}=1.90 \varepsilon_{c 0}$. As shown in Table 6 the total reinforcement steel area decreases in amount as the concrete creep increases. No convergence problems have been experienced, in all situations, the iterative procedure has converged in only six iterations.

\subsection{Example 4: Reinforced Concrete Staircase Cross- section}

The staircase core section, depicted in Fig. (17a), consists of the concrete matrix and 84 reinforcement bars with the same diameter. This section is subjected to biaxial bending and has to be designed to carry out the following design loads: $N=7731.1 \mathrm{kN}, M_{x}=10737.0 \mathrm{kNm}$, and $M_{y}=11725.5$ $\mathrm{kNm}$. Characteristic strengths for concrete and reinforcement bars are: $f_{c}^{\prime \prime}=23.46 \mathrm{MPa}, f_{y}=220.1 \mathrm{MPa}$ respectively.

The stress-strain curve for concrete which consists of a parabolic and linear-horizontal- part $(\gamma=0)$ was used in the calculation, with the crushing strain $\varepsilon_{c 0}=0.002$ and ultimate strain $\varepsilon_{c u}=0.003$. The Young modulus for reinforcing bars was $290 \mathrm{GPa}$ while the maximum strain was $\varepsilon_{u}= \pm 2 \%$. A bilinear elasto-perfect plastic stress-strain relationship for the reinforcement bars, both in tension and in compression, is assumed. This problem was also solved by Dundar and Sahin [5]. In their analysis the distribution of concrete stress is
Table 4. Example 3: Convergence Stability (Tol=1E-10)

\begin{tabular}{|c|c|}
\hline $\boldsymbol{A}_{\text {tot }}$ (initial) & No. Iterations \\
\hline \hline 0.01 & 7 \\
\hline 10 & 7 \\
\hline 100 & 7 \\
\hline 1000 & 9 \\
\hline 10000 & 10 \\
\hline-10 & 7 \\
\hline-100 & 7 \\
\hline-1000 & 9 \\
\hline-10000 & 10 \\
\hline
\end{tabular}

Table 5. Example 3: Confinement effect over $\boldsymbol{A}_{\text {tot }}$

\begin{tabular}{|c|c|c|}
\hline$\gamma$ & $\mathbf{A}_{\text {tot }}\left[\mathbf{c m}^{2}\right]$ & No. of Iterations \\
\hline \hline 0 & 37.521 & 5 \\
\hline 0.15 & 40.586 & 6 \\
\hline 0.30 & 43.788 & 7 \\
\hline 0.50 & 48.428 & 7 \\
\hline
\end{tabular}

Table 6. Example 3: Creep effect over $\boldsymbol{A}_{t o t}$

\begin{tabular}{|c|c|c|}
\hline $\boldsymbol{\varepsilon}_{c 0}\left(\varepsilon_{u}=\mathbf{1 . 9} \varepsilon_{c \mathbf{c}}\right)$ & $A_{\text {tot }}\left[\mathbf{c m}^{2}\right]$ & No. of Iterations \\
\hline \hline 0.002 & 40.586 & 6 \\
\hline 0.003 & 36.307 & 6 \\
\hline 0.004 & 35.189 & 6 \\
\hline 0.005 & 34.578 & 6 \\
\hline 0.007 & 34.115 & 6 \\
\hline
\end{tabular}

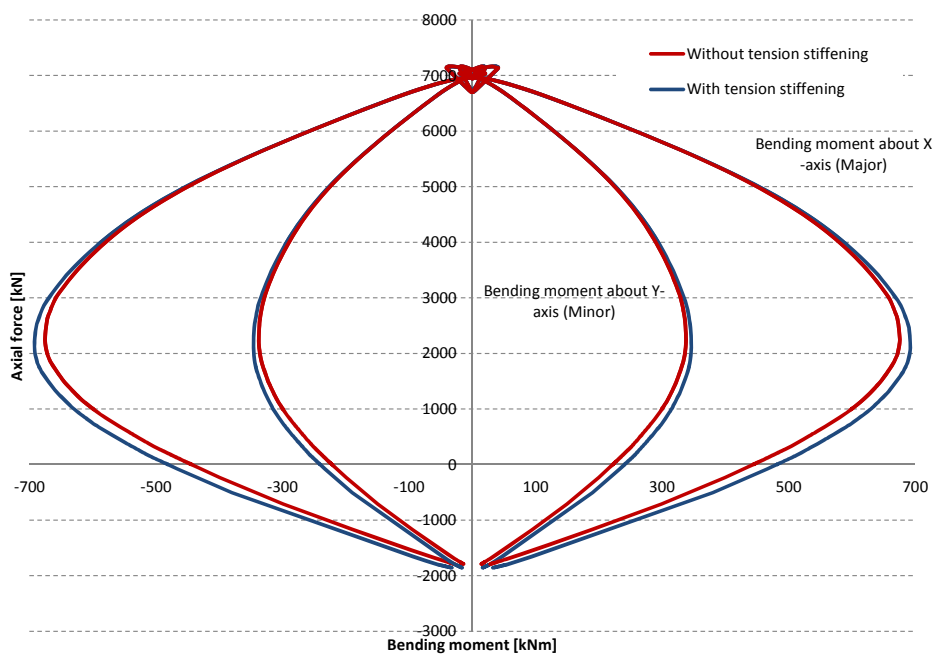

Fig. (15). Biaxial interaction curves for box cross-section $\alpha=26.56^{\circ}$. 


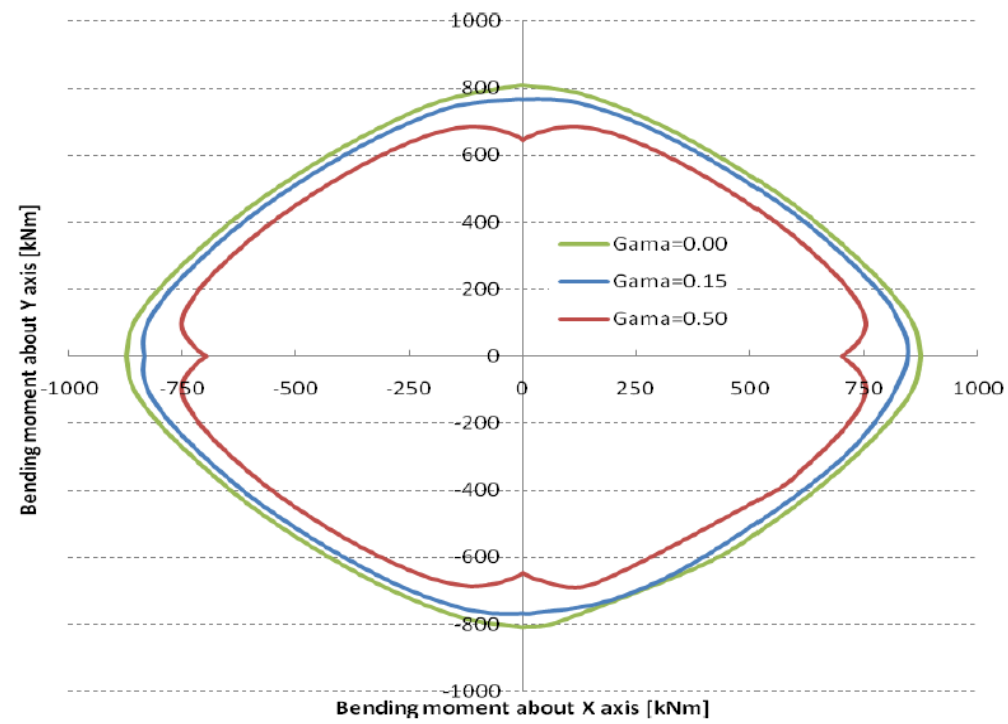

Fig. (16). Moment capacitiy contours of box cross-section with compressive axial force $N=2541.7 \mathrm{kN}$.

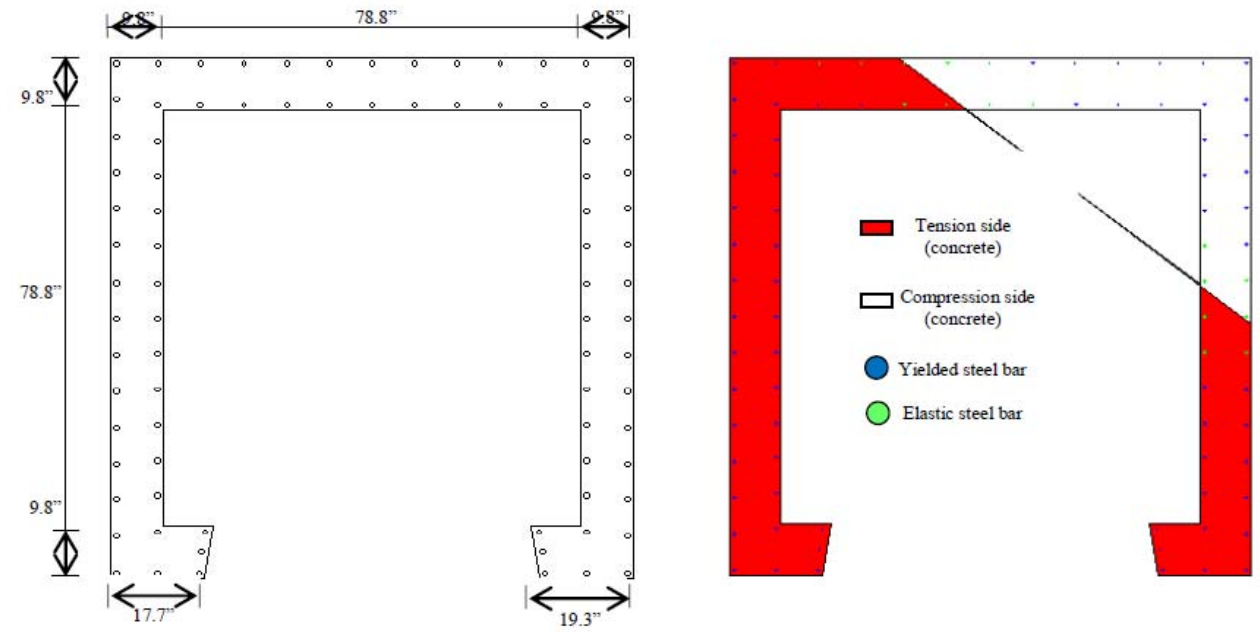

Fig. (17). Example 4. (a) Staircase core section; (b) Plastic status of section under design loads and $A_{t o t}=316.579 \mathrm{~cm}^{2}$.

assumed to be rectangular with a main stress of $f_{c}^{\prime \prime}=23.46 \mathrm{MPa}$

As shown in Table 7 the iterative process of design was started with $\phi_{x}=0$ and $\phi_{y}=0$, and $A_{t o t}=0.005 A_{\mathrm{g}}=92.62 \mathrm{~cm}^{2}$. The equilibrium tolerance has been taken as $1 E-4$. After only seven iterations, the numerical procedure converges to the solution $A_{\text {tot }}=316.579 \mathrm{~cm}^{2}$. This result is in very close agreement with solution $A_{t o t}=316.257 \mathrm{~cm}^{2}$ obtained by Dundar and Sahin [5]. Fig. (17b) shows the plastic status of the cross-section associated to the equilibrium between external design loads and internal forces with the total reinforcing area obtained after seven iterations. Fig. (18) presents the influence of the initial value of $A_{t o t}$ over convergence process. As it can be seen, starting the iterative process with $A_{t o t}=0.01 A_{g}=185.22 \mathrm{~cm}^{2}$ the numerical procedure converges, in 13 iterations, to the negative solution $A_{t o t}=-2226.85 \mathrm{~cm}^{2}$, whereas choosing as initial values $A_{t o t}=0.005 A_{g}$ or a very small value, $A_{\text {tot }}=0.0001$, the iterative process converges to the positive and real solution for this case.
In order to avoid the convergence to a negative value, the second approach implemented in the computer program has been tested. As already described, during the iterative process when a negative value for $A_{\text {tot }}$ occurred this value is used as a positive value for the next iterations.

Table 8 shows the behavior of this procedure with different initial values for total reinforcement area. As it can be seen the iterative process converges, in a few iterations, always to the positive solution, and the convergence stability is not affected by the quality of the initial approximation of the total reinforcement. Fig. (19) shows the corresponding moment capacity contour of this section, considering the reinforcement bars with diameter of $2.19 \mathrm{~cm}$, the compressive axial force $N=7731.1 \mathrm{kN}$ and different levels of confinement. Nonconvexity of the moment capacity diagrams is revealed even in this case by reducing the confinement in the concrete. 
Table 7. Example 4: Main Parameters Involved in the Iterative Process

\begin{tabular}{|c|c|c|c|c|}
\hline Iteration & $\phi_{\mathbf{x}}$ & $\phi_{\mathbf{y}}$ & $\mathbf{A}_{\text {tot }}\left[\mathbf{c m}^{2}\right]$ & Error (Eq. 18) \\
\hline \hline Initial & 0.000 & 0.000 & $0.005 \mathrm{~A}_{\mathrm{c}}=92.62$ & 1.000 \\
\hline 1 & $-5.644 \mathrm{E}-6$ & $-7.830 \mathrm{E}-6$ & -2858.381 & 1.006109 \\
\hline 2 & $-1.376 \mathrm{E}-5$ & $-6.785 \mathrm{E}-5$ & -940.168 & 0.249642 \\
\hline 3 & $-2.048 \mathrm{E}-5$ & $-1.466 \mathrm{E}-5$ & -124.761 & 0.331049 \\
\hline 4 & $-2.460 \mathrm{E}-5$ & $-1.814 \mathrm{E}-5$ & 310.799 & 0.183181 \\
\hline 5 & $-2.333 \mathrm{E}-5$ & $-1.772 \mathrm{E}-5$ & 315.943 & 0.0357735 \\
\hline 6 & $-2.335 \mathrm{E}-5$ & $-1.773 \mathrm{E}-5$ & 316.572 & 0.0001169 \\
\hline 7 & $-2.3352 \mathrm{E}-5$ & $-1.7732 \mathrm{E}-5$ & 316.579 & 0.0000232 \\
\hline
\end{tabular}

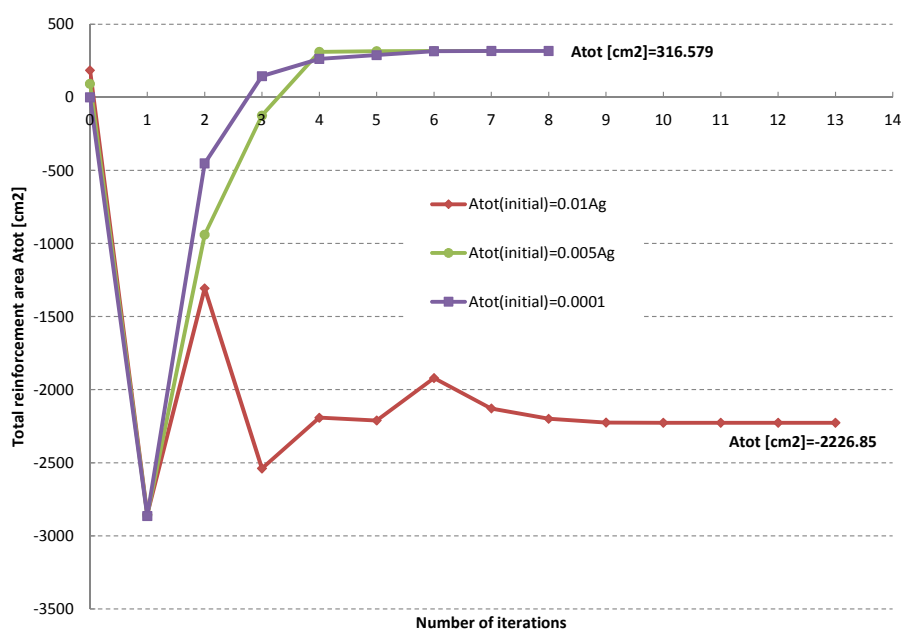

Fig. (18). Influence of the initial value of $A_{\text {tot }}$ over convergence process.

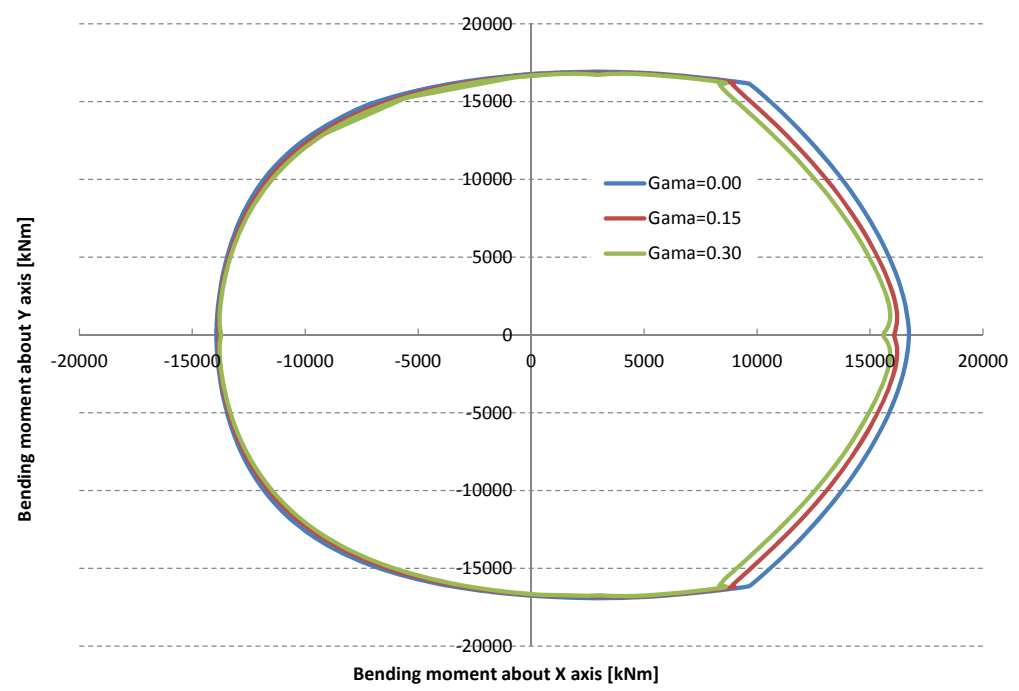

Fig. (19). Moment capacity contours for staircase cross-section with compressive axial force $N=7731.1 \mathrm{kN}$.

Table 9 presents the variations of the total steel reinforcement area, $A_{t o t}$, and the plastic status of the crosssection, considering different levels of the axial load. The bending moments have the same values as in the previously studied staircase core section $\left(M_{x}=10737.0 \mathrm{kNm}\right.$, and $M_{y}=11725.5 \mathrm{kNm}$ ). No convergence problems have been encountered using the proposed approach; a low number of iterations have been required to establish the equilibrium, 
Table 8. Example 4: Convergence Stability (Tol=1E-10)

\begin{tabular}{|c|c|}
\hline $\boldsymbol{A}_{\text {tot }}$ (initial) & No. Iterations \\
\hline \hline-10000 & 9 \\
\hline-1000 & 10 \\
\hline 10000 & 9 \\
\hline 1000 & 10 \\
\hline 0.01 & 9 \\
\hline 100000 & 10 \\
\hline-100000 & 10 \\
\hline
\end{tabular}

despite the fact that, in all cases, the iterative process has been started with curvatures $\phi_{x}=0$ and $\phi_{y}=0$, and a very restrictive equilibrium tolerance (i.e tol $=1 E-5$ ), has been considered.

\section{CONCLUSIONS}

A new computer method has been developed for the rapid design of composite steel-concrete cross-sections subjected to axial force and biaxial bending. The iterative algorithm, proposed herein, to design the steel reinforcement of composite steel-concrete sections under biaxial bending and axial force, as compared to other iterative methods, is very stable and the convergence is very fast. Convergence is assured for any load case, and is not sensitive to the initial/starting values, to how the origin of the reference loading axes is chosen or to the strain softening effect for concrete in compression or tension and residual stress distribution in encased steel elements. To the best knowledge of the author there are no divergence-proof procedures in the literature, and the proposed procedure represents a first attempt in this direction to develop automatic procedure for design of crosssections.

Due to presence of residual stresses, for encased steel section, a reduction of capacity strength of composite steel-

Table 9. Example 4: Variations of the Total Steel Reinforcement Area with Different Levels of the Axial Load

\begin{tabular}{|c|c|c|c|}
\hline $\mathbf{N}[\mathbf{k N}]$ & $A_{\text {tot }}\left[\mathrm{cm}^{2}\right]$ & No. of Iterations & Plastic Status \\
\hline 1000 & 559.741 & 6 & \\
\hline 10000 & 242.105 & 5 & \\
\hline 20000 & 12.814 & 4 & \\
\hline 30000 & 110.903 & 4 & \\
\hline 40000 & 505.181 & 6 & \\
\hline 50000 & 987.723 & 7 & \\
\hline-1000 & 636.151 & 6 & \\
\hline-10000 & 994.658 & 7 & \\
\hline-20000 & 1409.775 & 7 & \\
\hline
\end{tabular}


concrete cross-section was observed. The influence of residual stresses on the carrying capacity of cross- sections is most effective with higher axial load levels. From the numerical tests it may be concluded that the influence of the residual stress on the carrying capacity and inelastic behavior during the loading process is important and must be considered in the valuable advanced analysis of composite cross-sections.

The method has been verified by comparing the predicted results with the established results available from the literature and also numerous parametric studies have been performed in order to certify the convergence stability of the proposed approach. It can be concluded that the proposed numerical method proves to be reliable and accurate for practical applications in the design of composite steelconcrete beam-columns and can be implemented in the advanced analysis techniques of 3D composite frame structures.

\section{CONFLICTS OF INTEREST}

The authors confirm that this article content has no conflicts of interest.

\section{ACKNOWLEDGEMENT}

The writer gratefully acknowledges the support from Romanian National Authority for Scientific Research (ANCS and CNCSIS- Grant PNII-IDEI No. 193/2008) for this study.

\section{REFERENCES}

[1] C.G. Chiorean, G.M. Barsan. Large deflection distributed plasticity analysis of 3D steel frameworks, Comp. Struct., vol. 83, pp. 15551571, 2005.

[2] B.A. Izzudin, S.D, Lloyd. Efficient nonlinear analysis of elastoplastic 3D R/C frames using adaptive techniques, Comp. Struct., vol. 78, pp. 549-573, 2000.

[3] K.H. Kwak, T.C. Liauw. Computerized ultimate strength analysis of reinforced concrete sections subjected to axial compression and biaxial bending, Comp. Struct., vol. 21, pp. 1119-1127, 1985.

[4] J.M. Rotter, Rapid exact inelastic biaxial bending analysis, $J$. Struct. Eng., ASCE, vol. 111, pp. 2659-267, 1985.

[5] C, Dundar, B, Sahin. Arbitrarily shaped reinforced concrete members subject to biaxial bending and axial load, Comp. Struct., vol. 49, pp. 643-662, 1993.

[6] L. De Vivo, L. Rosati, Ultimate strength analysis of reinforced concrete sections subject to axial force and biaxial bending, Comp. Meth. Appl. Mech. Eng., vol. 166, pp. 261-287, 1998.
[7] J.A. Rodrigues, and J.D. Aristizabal-Ochoa, Biaxial interaction diagrams for short RC columns of any cross section, J. Struct. Eng., ASCE, vol. 125, pp. 672-683, 1999.

[8] A. Fafitis, Interaction surfaces of reinforced-concrete sections in biaxial bending, J. Struct. Eng., ASCE, vol. 127, pp. 840-846, 2001.

[9] S.F Chen, J.G. Teng, S.L. Chan. Design of biaxially loaded short composite columns of arbitrary section, J. Struct. Eng., ASCE, vol. 127, pp. 678-685, 2001.

[10] M.F. Sfakianakis. Biaxial bending with axial force of reinforced, composite and repaired concrete cross sections of arbitrary shape by fiber model and computer graphics, Adv. Eng. Software, vol. 33, pp. 227-242, 2002.

[11] J.L. Bonet, M.L. Romero, P.F. Miguel, M.A, Fernandez. A fast stress integration algorithm for reinforced concrete sections with axial loads and biaxial bending, Comp. Struct., vol. 82, pp. 213225, 2004.

[12] G. Alfano, F. Marmo, L. Rosati. An unconditionally convergent algorithm for the evaluation of the ultimate limit state of RC sections subject to axial force and biaxial bending, Int. J. Numer. Methods Eng., vol. 72, pp. 924-963, 2007.

[13] L. Rosati, F. Marmo, R. Serpieri. Enhanced solution strategies for the ultimate strength analysis of composite steel-concrete sections subject to axial force and biaxial bending, Comp. Methods Appl. Mech. Eng., vol. 197, pp. 1033-1055, 2008.

[14] F. Marmo, R. Serpieri, L. Rosati. Ultimate strength analysis of prestressed reinforced concrete sections under axial force and biaxial bending, Comp. Struct., vol. 89, pp. 91-108, 2011.

[15] L. Cedolin, G. Cusatis, S. Ecchelli, M. Roveda. Capacity of rectangular cross-sections under biaxially eccentric loads, ACI Struct. J., vol. 105, pp. 215-224, 2008.

[16] A.E. Charalampakis, V.K. Koumousis. Ultimate strength analysis of composite sections under biaxial bending and axial load, $A d v$. Eng. Softw., vol. 39, pp. 923-936, 2008.

[17] L. Pallares, P.F. Miguel, M.A.F, Prada. A numerical method to design reinforced concrete sections subjected to axial forces and biaxial bending based on ultimate strain limits, Eng. Struct., vol. 31, pp. 3065-3071, 2009.

[18] C.G. Chiorean. Computerised interaction diagrams and moment capacity contours for composite steel-concrete cross-sections, Eng. Struct., vol. 32, pp. 3734-3757, 2010.

[19] B. W. Skrabek, and S.A. Mirza. "Strength reliability of short and slender composite steel-concrete columns." Civil Engineering Report Senes. No. CE-90-1, Lakehead University, Thunder Bay, Ontario: p, 323, 1990.

[20] K.S. Virdi, and P.J. Dowling. "The ultimate strength of composite columns in biaxial bending." Procedures Institution of Civil Engineers (London), 56(May) : pp, 251-272, 1973.

[21] F.J. Vecchio, M.P. Collins. The modified compression field theory for reinforced concrete elements subjected to shear, $A C I J$., vol. 83, pp. 219-231, 1986.

[22] G.M. Eggert, P.R. Dawson, and K.K. Mathur. An adaptive descent method for nonlinear viscoplasticity. Int. J. Num. Meth. Eng., vol. 31, pp. 1031-1054, 1991.

[23] C.G. Chiorean. A fast incremental-iterative procedure for inelastic analysis of RC cross-sections of arbitrary shape, Acta Technica Napocensis: Civ. Eng. Architect, vol. 47, pp. 85-98, 2004.

\footnotetext{
Received: November 18, 2012

(C) Cosmin G. Chiorean; Licensee Bentham Open.
}

Revised: December 05, 2012

Accepted: December 06, 2012

This is an open access article licensed under the terms of the Creative Commons Attribution Non-Commercial License (http://creativecommons.org/licenses/by-nc/3.0/) which permits unrestricted, non-commercial use, distribution and reproduction in any medium, provided the work is properly cited. 